\title{
LA ESCUELA Y EL DESARROLLO HUMANO SOSTENIBLE: RETOS EDUCATIVOS A NIVEL LOCAL
}

\author{
School and sustainable development: educatives \\ challenges at local level
}

\section{L'école et le dévelopment soutenable: défis educatifs} au niveau local

\section{Pilar AZNAR MINGUET}

Universidad de Valencia. Facultad de Filosofía y Ciencias de la Educación. Departamento de Teoría de la Educación. C/. Blasco Ibáñez, 30. 46010 Valencia. Correo-e: pilar.aznar@uv.es

Fecha de aceptación definitiva: marzo de 2003

BIBLID [(1130-3743) 14, 2002, 151-183]

\section{RESUMEN}

El presente estudio responde al interés por conocer los procesos de aplicación del concepto/teoría del desarrollo sostenible a nivel local y el papel que puede desempeñar la escuela en la implementación de estos procesos en la comunidad en la que está inserta; tiene un respaldo teórico en torno a cuatro conceptos clave: a) el concepto de desarrollo sostenible; b) el concepto de "indicadores" para "medirlo"; c) el concepto de "eco-ética" o sustrato normativo para impulsarlo y d) el concepto de "glocalización" o referencia a lo "local desde lo global" para operativizarlo. Y tiene también un punto de mira o referente: la construcción de una escuela impulsora de la sostenibilidad del desarrollo a nivel local, de acuerdo con la filosofía del Programa 21 suscrito en la Cumbre de Río.

Palabras clave: desarrollo sostenible, escuela, participación educativa, relación escuela-comunidad. 


\section{SUMMARY}

Present study attempts to know the process of application the concept/theory of the sustainable development at local level and the role that school can accomplish to implement these process in the community where school stay; it has a theoretical foundation around four key concepts: a) the concept of the sustainable development; b) the concept of "indicators" to measure it; c) the concept of eco-ethic or normative frame to promote; d) the concept global-local to make operative it. And it has a point of view or concerning: the construction of a school propeler of the sustainable development at local level, in conformity with the fhylosophy of the Programme 21 subscribed to the summit conference of Río.

Key words: sustainable development, school, educational participation, relationship school-community.

SOMMAIRE

La présent étude essaye de connaître la processus d'application du concept de développement soutenable au niveau local et le rôle que l'école peut jouer dans la mise en oeuvre de ces processus dans la communauté dans laquelle elle est insérée; il a des fondements théoriques autour de quatre questions clef: a) le concept de développement soutenable; b) le concept d'indicateurs pour le mesurer; c) le concept echo-éthique ou substrat normatif pour le propulser et d) le concept "glocalización" ou référence à lui local depuis ce qui est global pour le rendre opérationnel. Et il a aussi un point de vue: la construction d'une école impulsive de l'aptitude à soutenir des opérations prolongées du développement au niveu local, en accord avec la philosophie du Programme 21 souscrit dans le Sommet de Río.

Mots clef: développement soutenable, école, participation educatif, relation école/commnauté.

\section{REFERENTES TEÓRICOS}

En la última década del siglo xx ha emergido con fuerza un nuevo concepto/idea con pretensiones de solucionar los graves problemas ecológicos y sociales que por diversas circunstancias (crecimiento económico mal planificado, desarrollo de la sociedad de consumo, impactos negativos sobre el medio, injusticia social...) han sumido a la civilización actual en una profunda crisis ecológica y social. El siglo xxi ha comenzado apostando abiertamente por un desarrollo sostenible promotor de una reconfiguración económica, tecnológica, social y también educativa, sobre la base de una nueva ética; la ética de la sostenibilidad, que, más que una ética ecológica, es una ética abarcadora de los diferentes ámbitos de interacción entre los seres humanos, entre éstos y la sociedad, sus instituciones, y el conjunto de sistemas bióticos (e incluso abióticos) que conforman el medio, tanto desde una óptica intra-generacional como desde una óptica inter-generacional. 


\subsection{El desarrollo sostenible}

El concepto de desarrollo sostenible se menciona inicialmente en la Declaración de Estocolmo sobre el Medio Humano (1972); se pone en evidencia en el 1을 y $2^{\circ}$ informe del Club de Roma (Meadows et al., 1972, 1993); se acuña y difunde como principio político en el Informe Brundtland (1987); se consolida como idea/filosofía/estrategia en la Declaración de Río sobre el Medio Ambiente y el Desarrollo (1992).

Pero es un concepto todavía hoy carente de un aparato teórico fundamentado en una experimentación suficiente y contrastada. No obstante su "mensaje", a pesar de la ambigüiedad del significado del término y de su engañosa simplicidad, o quizá por eso, ha tenido una gran aceptación tanto en los sectores económicos conservadores, como en los sectores sociales progresistas, por la posibilidad de dotarle de connotaciones coherentes con sus diversificadas propuestas. Lo cual ha contribuido a disparar una ingente cantidad de información sobre esta temática a través de fuentes impresas y electrónicas que han inundado editoriales y multiplicado "webs" en la red de redes.

Su conceptualización no está, pues, vacía de connotaciones socioeconómicas y éticas; cuestión que se plasma en los Informes sobre el Desarrollo realizados por organismos internacionales de orientación ideológico-política distinta, como son el Banco Mundial y el Programa de Naciones Unidas para el Desarrollo; el 1. refiere sus datos, desde la óptica de un crecimiento económico deseable, a Índices de Desarrollo Mundial, fundamentalmente económicos; el 2. refiere sus datos, desde la óptica de un desarrollo social deseable, a Índices de Desarrollo Humano, fundamentalmente sociales. Si bien la necesidad de integrar las dos cadenas de pensamiento (crecimiento y desarrollo) está propiciando una convergencia de posturas, como se desprende del Informe del Banco Mundial (2001) sobre la lucha contra la pobreza, y del Informe del PNUD (2001) sobre la necesidad de poner el adelanto tecnológico al servicio del desarrollo humano.

La sostenibilidad debe entenderse como un proceso equilibrado de interacciones dinámicas entre: los sistemas de la economía humana, los sistemas sociales formados por personas, grupos y países culturalmente diversos, y los sistemas medioambientales globales y locales. Desde esta óptica cabe incluir en la idea de desarrollo sostenible 4 elementos básicos (Aznar Minguet y Zabala, 1999): a) necesidad, que hace referencia a un desarrollo económico que tienda a satisfacer las necesidades esenciales a todos los miembros de una generación y asegurar las necesidades básicas de la generación siguiente; b) limitación, que hace referencia a un desarrollo compatible con el mantenimiento de los recursos naturales, los procesos ecológicos y la diversidad biológica; c) valor, que hace referencia la adopción de actitudes y comportamientos éticos de acuerdo a valores que promuevan un desarrollo respetuoso con la identidad, formas de vida, costumbres, creencias, de los diferentes pueblos y grupos sociales y promotor de justicia social y d) gestión, que hace referencia a la adopción de iniciativas políticas, personales, colectivas, educativas... para realizar la transición hacia formas más sostenibles del desarrollo. 
LA ESCUELA Y EL DESARROLLO HUMANO SOSTENIBLE: RETOS EDUCATIVOS A NIVEL LOCAL

\subsection{Sistemas de indicadores para medir el desarrollo sostenible}

Una cuestión ineludible ha sido pues encontrar la forma de evaluar dicha transición diferenciando las formas sostenibles de las no sostenibles del desarrollo; cuestión no exclusivamente técnica, ya que en la determinación de indicadores influye el enfoque desde el que se concibe el desarrollo sostenible, y los procedimientos en su determinación influyen a su vez en la formación de nociones sobre el desarrollo sostenible. La $1^{\underline{a}}$ premisa en este aspecto radica por tanto en la elección de los procedimientos de selección o definición de indicadores en base siempre a procesos que deberían ser explícitos, abiertos y transparentes.

Los indicadores de sostenibilidad hacen referencia a aspectos definibles y medibles de la realidad cuyos índices o niveles absolutos y la dirección en la que cambian sirven, tienen la función de indicar si el mundo, una ciudad, una empresa, una institución (por ejemplo, una escuela)..., tiene un desarrollo más o menos sostenible. Su función es importante, por cuanto: 1) propician información; 2) actúan como señal de aviso; 3) generan una mayor conciencia de lo que significa trabajar hacia la sostenibilidad; 4) constituyen una herramienta útil para la toma de decisiones (políticas, personales, educativas..., a plasmar en objetivos de desarrollo sostenible y puesta en marcha de acciones para alcanzarlo) y 5) conforman un valioso procedimiento de evaluación para detectar las formas de comportamiento compatibles con el mejor desarrollo humano sostenible deseable.

Pero dado que el desarrollo sostenible tiene que ver con múltiples aspectos y variables de la realidad social, económica, ecológica, sanitaria, educativa..., es preciso combinar indicadores, o determinar indicadores multivariados desde criterios generales y específicos. Los primeros tendentes a establecer: a) condiciones racionales en su aplicación y comprensión (uso de métodos reproducibles, coste razonable, facilidad de obtención e interpretación...); b) condiciones estandarizadas para su comparabilidad; y c) condiciones sistémicas integradoras de todos los aspectos y cambios involucrados en la complejidad de la realidad que tratan de evaluar. Y los segundos, dirigidos a establecer las condiciones que garanticen su adaptación al contexto, su referencia a objetivos previamente definidos, así como una relación coherente con los aspectos susceptibles de modificación.

En base a los diferentes tipos de criterios se han realizado diversas propuestas o modelos de sistemas de indicadores, entre los que cabe reseñar: el modelo propuesto por el Instituto Europeo del Medio Ambiente Urbano ${ }^{1}$ y el modelo propuesto por la Comisión para el Desarrollo Sostenible de la $\mathrm{ONU}^{2}$.

El primer modelo establece 3 categorías de indicadores de menor a mayor nivel de comparabilidad: los de área miden aspectos específicos de un contexto

1. European InSTITUTE for THE URBan ENvironment (1994) Urban European Indicators Program. Luxemburgo, Oficina de Publicaciones Oficiales de las Comunidades Europeas.

2. Comisión de Desarrollo Sostenible de la ONU-EUROSTAT (1998) Indicadores de Desarrollo Sostenible. Luxemburgo, Oficina de Publicaciones Oficiales de las Comunidades Europeas. 
concreto (ej.: ciudad, empresa, institución..., escuela); los de base miden aspectos comunes a varios contextos concretos que son política, ambiental, social y/o culturalmente homogéneos (ej.: región; empresas de un mismo sector, centros educativos de un mismo nivel); los de centro o núcleo dirigidos a medir aspectos que son comunes a todos los contextos, y son por lo tanto indicadores válidos a nivel local, regional o mundial. Este modelo ha sido aplicado en el Proyecto de Indicadores Europeos de sostenibilidad a una muestra de 12 ciudades europeas, con la finalidad de comenzar un control regular de un proceso hacia el desarrollo sostenible ${ }^{3}$.

El segundo modelo establece cuatro categorías de indicadores: sociales, económicos, medioambientales e institucionales. En cada una de las cuales se proponen tres tipos de indicadores: a) de impulso o presión (indican hacia dónde vamos; marcan la tendencia en relación a una variable); b) de estado o estructurales (indican las zonas de alarma o el punto a partir del cual es preciso actuar para corregir la tendencia) y c) de respuesta o de calidad (indican hacia dónde debemos ir; orientan las iniciativas a tomar para corregir la tendencia hacia la insostenibilidad). Este modelo se ha relacionado con el Programa $21^{4}$, distribuyendo sus diferentes capítulos en las 4 categorías de indicadores y estableciendo indicadores de impulso, de estado, y de respuesta, para cada uno de los capítulos. Y es importante recordar que el Capítulo 36 del Programa 21 suscrito en la Cumbre de Río en 1992 va referido a la educación y especifica tres ámbitos de atención prioritaria: 1) la reorientación de la educación hacia el desarrollo sostenible; 2) el fomento de la sensibilización de los ciudadanos y 3) la promoción de la capacitación y la formación para propiciar el desarrollo sostenible en todas las áreas de actividad humana. Ámbitos que pueden ser evaluados con los indicadores reseñados.

Los resultados obtenidos mediante la aplicación de los sistemas de indicadores son fuente de datos para diseñar planes de acción integrados, en los cuales también tienen que tener cabida acciones educativas: a) para fomentar los valores de la sostenibilidad; b) para la creación y/o modificación de actitudes que los desarrollen y c) para la permanente actualización de comportamientos que los apliquen.

3. Por ejemplo: \% de ONGs $/ 1.000 \mathrm{~h} ; \%$ de familias que practican la separación selectiva de residuos; $\%$ de empresas que aplican auditorías ambientales; $\%$ de personas que viven bajo el índice de pobreza; \% de personas con acceso a espacios verdes a no más de 5 minutos de su casa; índice de criminalidad anual; \% de calles peatonales $/ \mathrm{km}$ de calle...).

4. Dirección General de Política Ambiental (1993) Rio 92. Programa 21. Conferencia de las Naciones Unidas sobre el Medio Ambiente y el desarrollo. Madrid, MOPT. Y también en COMISIÓN DE LAs COMUNIDADES EuROpeas (1997) Programa 21. Los cinco primeros años de aplicación de la Agenda 21 en la Comunidad Europea. Bruselas, Dirección General XI. 


\subsection{Modelos eco-éticos para impulsar el desarrollo sostenible}

Ya en la propia definición de desarrollo sostenible está implícita la concepción moral y la actitud ética desde la que fomentar los valores de la sostenibilidad. Pero es una ética por construir desde respuestas alternativas a los modelos axiológicos tradicionales, cuyo proceso de fundamentación está siendo objeto de debate entre posturas defensoras de planteamientos antropocéntricos herederos de la tradición kantiana y enfoques éticos biocentristas (Aznar Minguet, 2003).

Entre los primeros está la ética discursiva, representada fundamentalmente por Habermas, Apple y Martín Sosa, entre otros. Habermas (1989) distingue dos actitudes básicas del ser humano en relación al medio: 1) objetivante, en la que la naturaleza se concibe como un objeto de conocimiento científico, y por tanto un medio al servicio del hombre y 2) normativa, que establece el uso de la naturaleza que mejor responde al bien común de la humanidad, desde el consenso en una comunidad de comunicación de actores (co-sujetos) cuyas relaciones, además de ser simétricas, están basadas en la reciprocidad y corresponsabilidad. Desde esta postura, en la comunidad ética sólo caben seres humanos, únicos sujetos de derechos.

Apple $(1993,1999)$ trata de superar los dualismos de Habermas, al considerar a los seres naturales como algo "similar" a los sujetos (aunque sin conferirles el estatus de co-sujetos). Y fundamenta una ética ecológica matizando los conceptos de responsabilidad y reciprocidad, con el concepto de solidaridad, partiendo del criterio normativo de que los sujetos defiendan los intereses del resto de los seres vivos a través del establecimiento de normas morales (que funcionarían como derechos encubiertos de la naturaleza). El problema aquí radica en la especificación de principios éticos lo suficientemente consensuados y estables desde los que poder evaluar las situaciones y los límites en la protección de los intereses naturales.

El enfoque de Martín Sosa $(1994,1997)$ apunta ya la posibilidad de ampliar la comunidad ética a otros seres vivos, estableciendo relaciones asimétricas dentro de ella, desde una concepción del ser humano como un ser que es, no frente a la naturaleza, sino en la naturaleza. El mundo humano sigue siendo el centro y fundamento de la ética, pero en cuanto que no es posible considerarlo fuera del medio ambiente de cuyo equilibrio depende su existencia.

Desde el modelo biocéntrico, Jonas (1995) trata de fundamentar una ética ecológica de base metafísica al relacionar el ser con el bien; desde esta óptica, todo lo que contiene la biosfera tiene un valor intrínseco porque existe y merece ser salvaguardado; todos los seres vivos conforman la comunidad biótica, entendida como comunidad de intereses en un marco común de interacciones interdependientes. Precisamente la tesis de Edgar Morin (1984) acerca del ser humano como ser eco-dependiente abre la puerta de la comunidad ética a todos los seres vivos.

Pero dado que los intereses humanos no son los únicos que importan moralmente, también desde este modelo se considera necesario establecer unos principios éticos o una eco-ética de mínimos (que no renuncie a máximos para 
contextos de pluralismo moral) 5 desde la que poder armonizar los derechos a la igualdad de todos los seres humanos con el derecho a disfrutar de un medio ambiente para el bienestar de todos los miembros de esta generación, sin poner en peligro el bienestar de la generación futura.

E implícita en esta exigencia está el derecho al desarrollo humano, imposible de alcanzar si no es en armonía con el desarrollo de todos los pueblos y con el respeto al equilibrio de la naturaleza; es decir, un desarrollo humano sostenible.

Estas cuestiones nos llevan a defender que la reflexión ética no puede ser ajena a la vida cotidiana, como tampoco puede ser ajena a la escuela; la cual, desde su relativa autonomía, es posible que pueda incorporar en sus Proyectos Educativos de Centro los principios éticos desde los que diseñar acciones educativas ajustadas a las nuevas exigencias de un desarrollo humano sostenible.

\subsection{De lo global a lo local: la contextualización del desarrollo sostenible}

Pero todas las argumentaciones en torno al desarrollo sostenible tienden a devaluarse si no se tienen en cuenta las diferencias que comporta referidas a la diversidad de las naciones, culturas y situaciones locales. Lo cual remite al desarrollo sostenible local (Almenar, et al., 2002).

En sentido amplio el desarrollo local se puede definir como un proceso de mejora de los niveles de vida de la población de una localidad que abarca cuatro áreas: a) política-administrativa: comprende las iniciativas municipales para la dinamización y coordinación de programas locales de desarrollo; requiere una política democrática de financiación y de descentralización del gasto público; b) económica: referida a las iniciativas locales para generar una capacidad productiva local; c) sociocultural: referida a la promoción de una igualdad de oportunidades, y al establecimiento de vínculos entre la sociedad civil para potenciar la capacidad de acción y participación en un desarrollo local equitativo y equilibrado; d) educativa: referida a la promoción de oportunidades de aprendizaje permanente para todos ${ }^{6}$.

El desarrollo local ha tratado de ser impulsado desde diversas orientaciones teóricas:

A. Positivista: parte de la ecuación “a mayor crecimiento económico, mejores condiciones sociales de vida, que a su vez propician un mayor crecimiento económico productor de progreso". Se asienta en la idea de un crecimiento sin límites al uso y consumo de bienes naturales; es el enfoque seguido en las políticas desarrollistas dirigidas a resolver los problemas de

5. Cortina, A. (1990) Ecologismo y derecho de los pueblos, Claves, 8. Etxeberría, X. (1994) La ética ante la crisis ecológica, Revista Bakeaz, 5.

6. CONSEjo de la UnIÓN EuROPEa (1997) Conclusiones del Consejo de 17 de febrero de 1997 sobre el desarrollo de las comunidades locales por medio de la educación y la formación, DOCE, $\mathrm{n}^{\circ}$ C070 (6-31997) P. 003-004. Documento 397 y 0306 (01). 
países en vías de desarrollo a través de un apoyo económico externo que fuera productor de progreso (San Pedro, 1982). Pero el fracaso de las mismas, patente por las consecuencias generadoras de la deuda pública contraída, ha cuestionado el hecho de que el progreso fuera neutro, puesto que depende del uso que se haga de los factores que lo propician.

B. Ecodesarrollo: iniciada en la década de los años setenta (Naredo, 1996) opone la variable ecológica a la variable económica a través de estrategias de potenciación de recursos propios, de la participación ciudadana, de cambios en los modelos de consumo y del respeto a la cultura y a los valores locales. Pero su evolución hacia posturas radicales contra la explotación económica, la injusticia social y el desarrollo ecológicamente inapropiado le han situado fuera de la organización social y económica vigente.

C. Enfoques sistémicos: parten de la idea de interacción equilibrada entre los factores involucrados en el desarrollo para que sea humanamente sostenible. Cabe destacar la tesis de M. Bunge (1989) que defiende un "interaccionismo sistémico" promotor de un desarrollo armónico entre los cuatro factores que conforman el medio ambiente: el desarrollo económico, el sociocultural, el político y el biológico. La tesis de Meadows (1993) defiende, desde una óptica planetaria, un "interaccionismo macroecosistémico" que garantice la sosteniblidad del desarrollo evitando disfunciones por el abuso en el consumo de recursos y la producción incontrolada de residuos. Sus informes han generado las tesis contra la insostenibilidad: la tesis del mundo vacío, la tesis del mundo lleno, y la tesis del Factor $4^{7}$. Manzini (1992) parte de un enfoque intervencionista al considerar que el desequilibrio medio-ambiental es producto de impactos humanos y propone el desarrollo de programas de cambios de actitudes desde los que fomentar los valores de la sostenibilidad.

Las tendencias actuales en el desarrollo local apuntan a una serie de factores que caracterizan esos nuevos valores: a) participación ciudadana; b) asociacionismo en redes; c) enfoque sistémico en la planificación de las acciones; d) consenso político y social en las decisiones; e) referencia global del desarrollo local; y f) una interacción dialógica permanente a través de procesos democráticos de confrontación y consenso. Estos factores están queriendo ser impulsados desde las Agendas 21 locales que constituyen, a nivel mundial, la respuesta de las comunidades locales al Plan de Acción del Programa 21 suscrito en la Cumbre de Río; y a nivel europeo, la respuesta al V Programa Marco de Medio Ambiente y Desarrollo Sostenible (MMA 1997) ${ }^{8}$. La Agenda 21 Local es un mecanismo que implica

7. WeIZÄCKER, E. U.; LOVINS, L. H. y Lovins, A. B. (1997) Factor 4. Duplicar el bienestar con la mitad de los recursos naturales. Informe del Club de Roma. Barcelona, Galaxia Gutemberg.

8. Recientemente la Unión Europea ha publicado el 6o Programa Marco de Medio Ambiente y Desarrollo Sostenible que comprende acciones hasta el 2010. COMISIÓN DE LAS COMUNIDADES EuROPEAS 
procesos estratégicos de fomento y control holístico del desarrollo sostenible desde enfoques sistémicos. En su desarrollo, dentro del ámbito europeo, cabe destacar tres acontecimientos clave ${ }^{9}$ :

1. - La Carta de Aarlborg (1994), constituida en la 1. ${ }^{-}$Conferencia Europea sobre ciudades y villas sostenibles; representa la firma de un compromiso para trabajar hacia la sostenibilidad a nivel municipal ${ }^{10}$.

2. $\quad$ El Plan de Acción de Lisboa (1996), configurado en la 2. ${ }^{a}$ Conferencia Europea sobre ciudades y villas sostenibles; promueve la aplicación de "herramientas" que determinen modelos, instrumentos y técnicas para su implantación y desarrollo, con la potenciación de la participación ciudadana y la promoción de valores pertinentes a través de la educación.

3." La Declaración de Hannover (2000), expresada en la 3. ${ }^{\text {a }}$ Conferencia PanEuropea sobre ciudades y villas sostenibles; potencia el rol de los gobiernos locales en el desarrollo sostenible incidiendo en los problemas de exclusión social, el desarrollo de sistemas de indicadores que establezcan el perfil de sostenibilidad local, y la construcción de códigos de «buenas prácticas ambientales" como guías de gestión en todos los ámbitos de interacción humana.

La diversidad de realidades locales y sus problemáticas específicas han propiciado el desarrollo de modelos de implantación de planes de sostenibilidad y de participación ciudadana diferenciados. Aunque para garantizar unas condiciones mínimas de calidad, existen a nivel internacional unas pautas y normativa de acción para la aplicación de la Agenda 21 local $^{11}$, que precisan la sucesión interrelacionada de una serie de fases en su desarrollo ${ }^{12}$, previo a las cuales establecer un

(2001) Medio Ambiente 2010: el futuro está en nuestras manos. VT Programa Comunitario de Medio Ambiente 2001-2010. Luxemburgo, Oficina de Publicaciones de las Comunidades Europeas.

9. www.sustainable-cities.org. Se trata de una página web que recoge los textos de las tres conferencias que se citan a continuación.

10. Este compromiso implica la adhesión municipal a la "Carta de Aarlborg»; la constitución de un foro de participación ciudadana; la realización de un diagnóstico ambiental que incluya factores económicos, ecológicos y socioculturales; la especificación de indicadores para la evaluación de la sostenibilidad del desarrollo; la realización de auditorías ambientales; la concreción de objetivos de sostenibilidad local; el diseño y aplicación de un plan específico de acción y un seguimiento y revisión del mismo.

11. Cabe destacar, entre los diferentes modelos-guía nacionales e internacionales para la puesta en marcha de Agendas 21 locales: LoCAL GOVERnEMENT BOARD (1994) Local Agenda 21. Principles and process; a step by step Guide. Lutton, Edic. LGMB. También ICLEI (1998) Guia europea para la planificación de las Agendas 21 Locales. Bilbao, Editorial Bakeaz. Y también Federación Española de Municipios y Provincias (2000) Código de buenas prácticas ambientales para la normalización de la gestión medioambiental en los municipios de España. Publicaciones de la FEMP.

12. Entre las que cabe destacar: a) la constitución de un comité de gestión operativo para la sostenibilidad; b) la adhesión formal a la red de municipios sostenibles; c) la constitución de una estructura de participación ciudadana; d) la realización de auditorias mediante el uso de indicadores de sostenibilidad; e) el diseño, aplicación y seguimiento de un plan de acción. 
debate sobre el significado de la sostenibilidad y la forma de conseguir el desarrollo sostenible en el municipio; dicho debate permite generar un espacio de reflexión y de participación para considerar las prioridades sobre las que actuar y elaborar una "declaración ambiental" como documento de compromiso previo que refleje una visión holística del municipio que involucre, a nivel de autoridades locales, los proyectos, planes, políticas y actividades del municipio, y a nivel de la comunidad de ciudadanos - agentes y grupos sociales--, acciones de información y de formación intensiva y extensiva sobre el significado de la sosteniblidad.

La importancia de las cuestiones planteadas hace preciso la realización de investigaciones que puedan evidenciar y contrastar la idoneidad de los procesos desarrollados $^{13}$. Desde la perspectiva educativa cobra una especial relevancia la cuestión de la participación ciudadana, y especialmente, la participación de las agencias educativas (formales y no formales) de la localidad en la implementación del desarrollo sostenible local, desde las posibles iniciativas y acciones a realizar en los propios centros educativos, hasta la participación representativa en los foros cívicos, o la creación de foros paralelos en los centros educativos que involucren a toda la comunidad educativa. La educación no debería quedar al margen del camino hacia la sostenibilidad de desarrollo; las administraciones educativas deberían desarrollar políticas educativas explícitas favorables al desarrollo de estos procesos; pero aun la falta de las mismas no debería paralizar las iniciativas que la relativa autonomía de los centros educativos pueda impulsar, desde sus Proyectos Educativos de Centro.

\subsection{La educación en los municipios "sostenibles"}

La sostenibilidad es una responsabilidad compartida. Las agencias educativas no pueden evadirse. Pero hace falta reorientar la educación, la concienciación y la capacitación de los ciudadanos hacia la comprensión, análisis crítico y apoyo personal y público a estos procesos; esta reorientación se asienta en tres principios base $^{14}$ : a) el medio ambiente está constituido por diversos factores que están integrados: físico, social, económico, cultural y humano; b) las acciones a realizar a nivel local han de tener siempre un referente global y c) la educación formal y no formal ha de ir dirigida a la modificación de actitudes y a la formación de los sujetos para

13. Uno de los primeros estudios sobre la implantación de procesos de desarrollo sostenible a nivel local permite ya disponer de datos comparativos sobre diferentes formas de actuación y sobre las dificultades encontradas en municipios con planes de implantación más avanzados. Font, N.; Querol, C. y Subirats, J. (2000) El desarrollo de los procesos de implantación de la Agenda 21 local en los municipios. Informe de Investigación realizado por el equipo de Análisis Político de la Universidad Autónoma de Barcelona. Diputación de Barcelona.

14. Capítulo 36 del Programa 21 —documento suscrito en la Cumbre de Río de 1992-, en el que se plantean medidas para fomentar la educación hacia el medio ambiente (Ministerio del Medio Ambiente, 1997a). 
evaluar y apoyar el desarrollo sostenible. Desde estos principios se pretende que la educación para el desarrollo sostenible esté presente en el ámbito formal de los "Currícula" de educación infantil, primaria, secundaria y universitaria; en el ámbito no formal a través de programas de educación de adultos; en el ámbito informal a través de campañas de sensibilización desde los diferentes medios de comunicación. Implica la integración de la educación en la gestión del desarrollo sostenible a nivel local, y la participación de la comunidad educativa en los procesos de decisión de planes de acción locales, y requiere de las agencias educativas la asunción de una serie de funciones (Aznar Minguet, 2003): a) Colaboración entre los agentes educativos locales; b) interacción entre los ámbitos formal, no formal e informal de la educación en el municipio; c) integración de las "educaciones" (Educación Ambiental; Educación para la Salud; Educación Moral; Educación del Consumidor; Educación Intercultural; Educación para la Paz...); d) implementación de la participación de la comunidad educativa de los centros escolares en los planes de sostenibilidad de los municipios donde están enclavados; e) búsqueda de alternativas a la "transversalidad curricular".

\section{REFERENTES METODOLÓGICOS}

Estas reflexiones nos han llevado a buscar los elementos que pueden conformar una política educativa en las escuelas dirigida al desarrollo sostenible; política educativa de doble aplicación: por una parte, en el propio centro educativo a través de una gestión ambiental integral y de una educación ambiental integrada en el currículum; y, por otra parte, en la localidad en la que el centro se ubica a través de la posible participación en los foros cívicos de apoyo al desarrollo de las Agendas 21 locales.

Partiendo de estas consideraciones, nos hemos propuesto, mediante el análisis de los resultados obtenidos en la aplicación de un cuestionario dirigido a una muestra estadísticamente representativa de directores escolares ${ }^{15}$, los siguientes objetivos: A) Identificar el grado de información que sobre el desarrollo sostenible se dispone en los centros educativos. B) Evidenciar la existencia o no existencia en la escuela de una política en relación al medio ambiente y el desarrollo sostenible. C) Averiguar la posible realización de actividades educativas curriculares o extracurriculares en relación a esta temática. D) Conocer el grado de información que se dispone en las escuelas sobre las posibles iniciativas de las administraciones municipales en la implantación y desarrollo de la Agenda 21 local. E) Averiguar la posible participación de la escuela en los foros cívicos del municipio para la implantación y desarrollo de dichos planes locales de sostenibilidad.

15. La muestra recoge las opiniones de 150 directores de centros educativos de enseñanza primaria de la provincia de Valencia. 
Aunque de manera incipiente, se vienen desarrollando experiencias e iniciativas diversas tendentes a operativizar a nivel local el plan de acción que se propuso en la Conferencia de Río para caminar hacia la sostenibilidad del desarrollo ${ }^{16}$. Nuestro análisis ha pretendido realizar un bosquejo global de la situación de los centros educativos frente a los requerimientos del desarrollo humano sostenible, para sugerir líneas y planes de acción que los involucren e implementen su participación ${ }^{17}$. No obstante se trata de un estudio que reviste un carácter exploratorio sobre una cuestión cuya novedad es patente y que precisaría de exploraciones posteriores de mayor alcance y nivel de generalización para conocer la evolución de la problemática planteada, aplicar modelos de participación de la escuela en los planes de acción sostenibles de los municipios donde se ubica, y evaluarlos.

Sometido el cuestionario al análisis de expertos para asegurar la validez de contenido del conjunto, obtuvimos un instrumento de 32 ítems, dividido en tres secciones $^{18}$ (Anexo 1): la primera referida al tipo de política ambiental, explícita o implícita, sistemática o esporádica, consensuada o no consensuada, reflejada o no reflejada en documentos oficiales, que el centro educativo puede desarrollar a través de la realización de actividades curriculares o extracurriculares y de la especificación de normativa relacionada con la protección, control, gestión y educación ambiental; partiendo siempre de la consideración de que el medio ambiente incluye aspectos ecológicos, económicos, culturales, sociales o humanos y éticos. La segunda centrada en el tipo de programas, iniciativas y actividades educativas que realizan los centros educativos relacionadas con el desarrollo sostenible, así como su grado de integración en posibles actuaciones conjuntas de la comunidad educativa. La tercera contenedora de aspectos relacionados con la información y posible participación de los centros educativos en los procesos de implantación y desarrollo de las Agendas 21 locales a través de los foros cívicos u otros sistemas que posibiliten la implicación de la escuela en la búsqueda de soluciones a los problemas que plantea la sostenibilidad del desarrollo en su municipio.

16. Cabría citar el Proyecto “Educar para la sostenibilidad” (1997-1999), financiado por la Unión Europea en el marco del Programa Sócrates y vinculado a la Agenda 21, y en el que participaron 24 centros educativos de cuatro regiones europeas: Inglaterra, Suecia, Dinamarca y España (concretamente el Instituto de Bachillerato y el Colegio público Ambaixador Beltrán del municipio valenciano de Almazora). El objetivo era involucrar a la población local en la búsqueda de formas de vida más sostenibles.

17 La participación local de ciudadanos y grupos sociales en los procesos de desarrollo sostenible y en los beneficios de su implementación conforma hoy uno de los derechos de la llamada "Tercera Generación» (Ander-Egg, 1996; Touriñan López, 1999; López Barajas y Ruiz Corbella, 2000).

18. El cuestionario utilizado constituye una versión adaptada a los centros educativos de un instrumento previo elaborado por el Equipo de Investigación de Análisis Político de la Universidad Autónoma de Barcelona para la realización de un Informe encargado por la Diputación de Barcelona sobre el desarrollo de los procesos de implantación de las Agendas 21 locales en los municipios españoles. 
El análisis realizado ${ }^{19}$ tras el procesamiento de datos nos lleva a los siguientes resultados:

En la Primera Parte del Cuestionario las características mayormente reseñables que hemos encontrado refieren que la mayoría de escuelas dispone de una política ambiental $(78,7 \%)$, frente a las que no disponen de ella $(20,7 \%)$ :

\section{CUADRO 1}

El centro dispone de una política ambiental reflejada en documentos oficiales

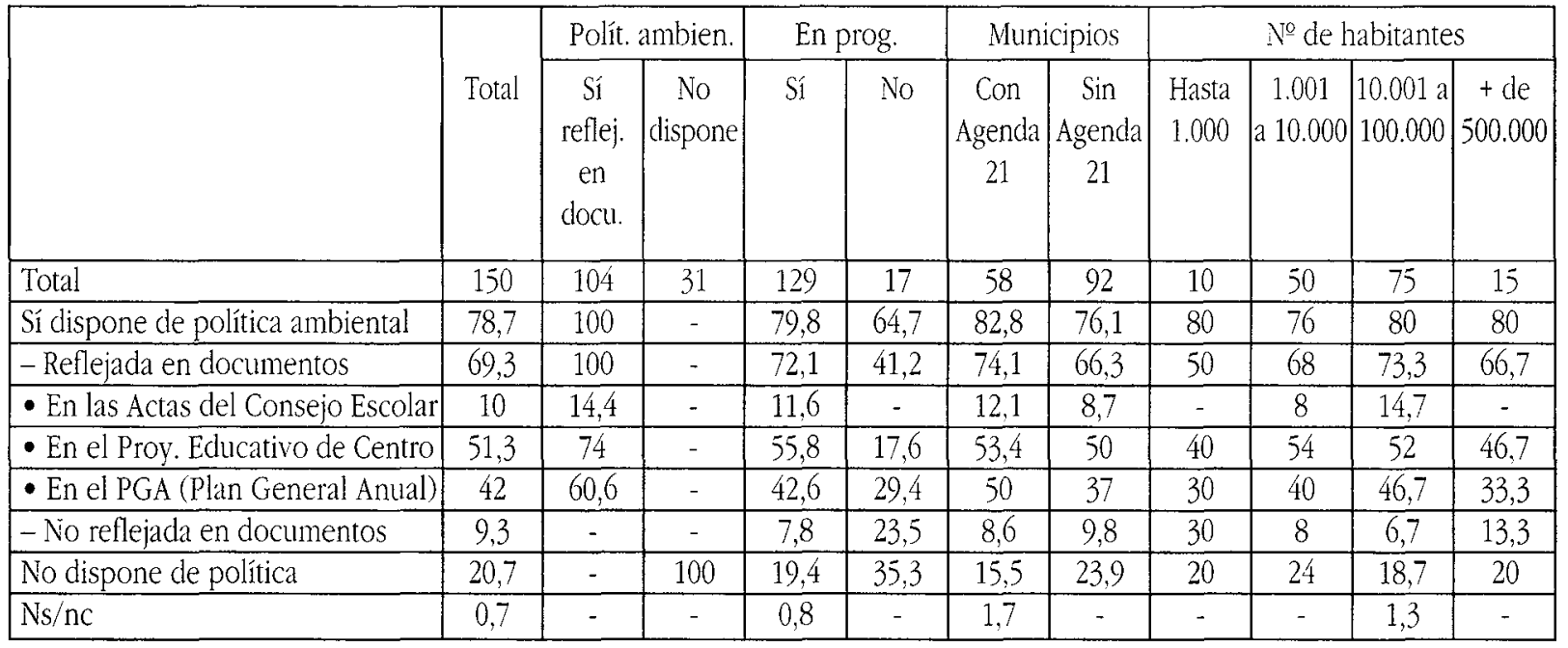

Siendo significativa su constancia en documentos oficiales. El 74\% de ellas la refleja en el PEC; el 14,4\% lo hace en las Actas del Consejo Escolar y el 60,6\% en el Plan General Anual; existiendo en las que disponen de política ambiental una mayor proporción que incluyen en sus programaciones de aula actividades relacionadas con la educación ambiental y el desarrollo sostenible que las escuelas que no disponen de política ambiental.

Estas escuelas operativizan la política ambiental mayormente en actividades complementarias esporádicas (74\%); aunque hay un porcentaje considerable (40\%) que la incluye en actividades curriculares sistemáticas y en la gestión de recursos $(25,3 \%)$. No se detectan diferencias notables entre el tamaño y la existencia de Agenda 21 local en el municipio:

19. Se ha realizado, entre otros, un análisis descriptivo de relaciones en base a tabulaciones cruzadas con test de contrastación para averiguar las características que presentan las variables estudiadas. El contraste de diferencias porcentuales se ha realizado a un nivel de significación del 5\%, una probabilidad de que se cumpla la hipótesis nula del 5\% y un nivel cle confianza del 95\%. 


\section{CuAdro 2}

Acciones en las que se operativiza la política ambiental

\begin{tabular}{|c|c|c|c|c|c|c|c|c|c|c|c|}
\hline & \multirow[b]{2}{*}{ Total } & \multicolumn{2}{|c|}{ Polit ambien. } & \multicolumn{2}{|c|}{ En prog. } & \multicolumn{2}{|c|}{ Municipios } & \multicolumn{4}{|c|}{ № de habitantes } \\
\hline & & $\begin{array}{l}\text { Sí } \\
\text { reflej. } \\
\text { en } \\
\text { docu. }\end{array}$ & $\begin{array}{c}\text { No } \\
\text { dispone }\end{array}$ & Sí & No & $\begin{array}{c}\text { Con } \\
\text { Agenda } \\
21\end{array}$ & $\begin{array}{c}\text { Sin } \\
\text { Agenda } \\
21\end{array}$ & $\begin{array}{l}\text { Hasta } \\
1.000\end{array}$ & $\begin{array}{c}1.001 \\
a 10.000\end{array}$ & $\begin{array}{l}10.001 \mathrm{a} \\
100.000\end{array}$ & $\begin{array}{c}+ \text { de } \\
500.000\end{array}$ \\
\hline Total & 150 & 104 & 31 & 129 & 17 & 58 & 92 & 10 & 50 & 75 & 15 \\
\hline Activi curricul. sistemáticas & 40 & 53.8 & 3.2 & 43.4 & 11,8 & 36,2 & 42,4 & 40 & 42 & 40 & 33.3 \\
\hline Act. curr. complement. esporádicas & 74 & 74 & 77.4 & 75,2 & 64,7 & 72,4 & 75 & 60 & 82 & 70.7 & 73.3 \\
\hline En la gestión de recursos & 25.3 & 26.9 & 22.6 & 26.4 & 17.6 & 22.4 & 27,2 & 30 & 16 & 32 & 20 \\
\hline Otros & 10 & 9.6 & 12.9 & 9.3 & 17.6 & 12,1 & 8,7 & - & 8 & 13.3 & 6,7 \\
\hline $\mathrm{Ns} / \mathrm{nc}$ & 1.3 & - & 6.5 & 1.6 & - & 1.7 & 1.1 & 10 & - & 1.3 & - \\
\hline
\end{tabular}

Un tercio de centros educativos de la muestra dispone de normas explícitas consensuadas por la comunidad educativa en relación con la protección, control y gestión de recursos ambientales; una proporción considerable aunque no significativa de ellos, esta ubicado en los municipios que han implantado una Agenda 21 local. Pero sí es significativo que los centros que disponen de normas explícitas y consensuadas dispongan también de una política ambiental reflejada en documentos oficiales $(46,2 \%)$; y que los centros educativos en los que no existen normas explícitas tampoco dispongan mayoritariamente de una política ambiental $(83,9 \%)$; de igual modo es significativo el número de centros que disponiendo de una normativa explícita y consensuada han incluido actividades de educación ambiental para el desarrollo sostenible en sus programaciones de aula $(37,2 \%)$; y que los centros educativos en los que no existen normas explícitas no han incluido actividades de este tipo en sus programaciones $(88,2 \%)$.

\section{Cuadro 3}

El centro dispone de normativa explícita consensuada

\begin{tabular}{|c|c|c|c|c|c|c|c|c|c|c|c|}
\hline & \multirow[b]{2}{*}{ Total } & \multicolumn{2}{|c|}{ Polít. ambien. } & \multicolumn{2}{|c|}{ En prog. } & \multicolumn{2}{|c|}{ Municipios } & \multicolumn{4}{|c|}{ № de habitantes } \\
\hline & & $\begin{array}{l}\text { Sí } \\
\text { reflej. } \\
\text { en } \\
\text { docu. }\end{array}$ & $\begin{array}{c}\text { No } \\
\text { dispone }\end{array}$ & Si & Xo & $\begin{array}{c}\text { Con } \\
\text { Agendal } \\
21\end{array}$ & $\begin{array}{c}\text { Sin } \\
\text { Agenda } \\
21\end{array}$ & $\begin{array}{l}\text { Hasta } \\
1.000\end{array}$ & $\begin{array}{c}1.001 \\
\mathrm{a} 10.000\end{array}$ & $\begin{array}{l}10.001 \mathrm{a} \\
100.000\end{array}$ & $\begin{array}{c}+ \text { de } \\
500.000\end{array}$ \\
\hline Total & 150 & 104 & 31 & 129 & 17 & 58 & 92 & 10 & 50 & 75 & 15 \\
\hline Sí, normas expl./consensuadas & 33.3 & 46,2 & 3,2 & 37,2 & 5,9 & 41,4 & 28,3 & 10 & 34 & 34,7 & 40 \\
\hline Sí, normas expl./no consens. & 12 & 13,5 & 9,7 & 11,6 & 5,9 & 8,6 & 14,1 & 30 & 6 & 16 & - \\
\hline No existen normas explícitas & 50,7 & 35,6 & 83,9 & 46,5 & 88,2 & 44,8 & 54,3 & 60 & 56 & 45,3 & 53,3 \\
\hline $\mathrm{Ns} / \mathrm{nc}$ & 4 & 4,8 & 3,2 & 4,7 & - & 5,2 & 3,3 & - & 4 & 4 & 6,7 \\
\hline
\end{tabular}


Los organismos que desarrollan la política ambiental en los centros son mayoritariamente los Equipos de Ciclo (74,7\%), el Equipo Directivo del centro $(26,7 \%)$ y el Consejo Escolar (18,7\%); siendo significativo que los que desarrollan la política ambiental a través de los Equipos de Ciclo sean los centros que mayoritariamente la reflejan en documentos oficiales $(84,6 \%)$ así como los que también mayoritariamente incluyan actividades de educación ambiental para el desarrollo sostenible en sus programaciones de aula (77,5\%); y, aunque no es significativo, se puede observar una cierta tendencia a que los centros de estas características estén ubicados en poblaciones de tamaño medio.

Son muy pocos los centros que no tienen nunca en cuenta en sus decisiones criterios ambientales (2,7\%). El 34,7\% decide siempre en base a estos criterios, y el $60 \%$ sólo a veces y en algunos aspectos. Nuevamente se observa que, de forma significativa, los que más tienen en cuenta estos criterios disponen además de una política ambiental reflejada en documentos oficiales e incluyen actividades coherentes en sus programaciones:

CUADRO 4

Decisiones basadas en criterios ambientales

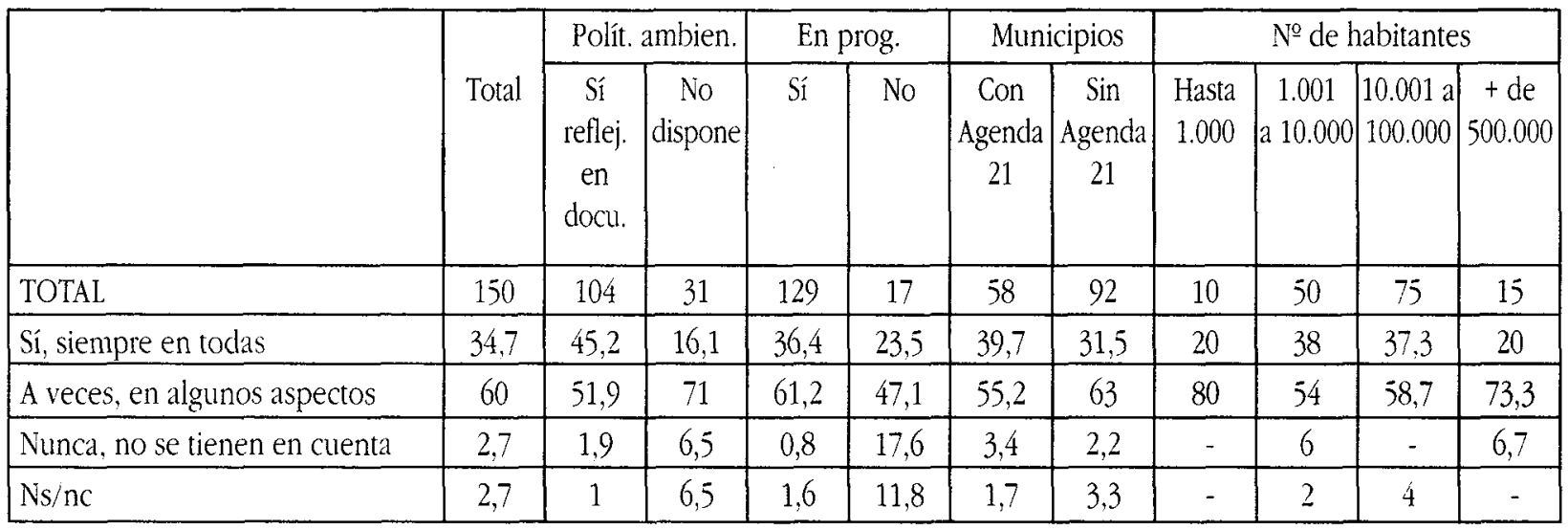

Es minoritario el porcentaje de centros que han iniciado un debate sobre el desarrollo sostenible (18,7\%); el mayor porcentaje de respuestas corresponde a los centros que, o no han iniciado un debate al respecto $(39,3 \%)$, o que consideran que habría que iniciarlo $(41,3 \%)$; siendo significativo estadísticamente que en el grupo minoritario se encuentren más centros que disponen de una política ambiental reflejada en documentos oficiales $(23,1 \%)$ y ubicados en municipios de tamano mediano $(25,3 \%)$ : 


\section{CUADRO 5}

Debate sobre el desarrollo sostenible

\begin{tabular}{|c|c|c|c|c|c|c|c|c|c|c|c|}
\hline & \multirow[b]{2}{*}{ Total } & \multicolumn{2}{|c|}{ Polít. ambien. } & \multicolumn{2}{|c|}{ En prog. } & \multicolumn{2}{|c|}{ Municipios } & \multicolumn{4}{|c|}{ № de habitantes } \\
\hline & & $\begin{array}{c}\text { Sí } \\
\text { reflej. } \\
\text { en } \\
\text { docu. }\end{array}$ & $\begin{array}{c}\text { No } \\
\text { dispone }\end{array}$ & Sí & No & $\begin{array}{c}\text { Con } \\
\text { Agenda } \\
21\end{array}$ & \begin{tabular}{|c|} 
Sin \\
Agenda \\
21
\end{tabular} & $\begin{array}{l}\text { Hasta } \\
1.000\end{array}$ & \begin{tabular}{|l|}
1.001 \\
10.000
\end{tabular} & $\begin{array}{l}10.001 \mathrm{a} \\
100.000\end{array}$ & $\begin{array}{c}+\mathrm{de} \\
500.000\end{array}$ \\
\hline Total & 150 & 104 & 31 & 129 & 17 & 58 & 92 & 10 & 50 & 75 & 15 \\
\hline Sí & 18,7 & 23,1 & 6,5 & 20,9 & 5,9 & 24,1 & 15,2 & - & 12 & 25,3 & 20 \\
\hline No & 39,3 & 36,5 & 41,9 & 38 & 52,9 & 39,7 & 39,1 & 60 & 36 & 36 & 53.3 \\
\hline No, pero habría que iniciar & 41,3 & 39,4 & 51.6 & 40,3 & 41,2 & 36,2 & 44,6 & 40 & 52 & 37,3 & 26.7 \\
\hline $\mathrm{Ns} / \mathrm{nc}$ & 0,7 & 1 & - & 0,8 & - & - & 1,1 & - & - & 1,3 & - \\
\hline
\end{tabular}

Es reseñable que los que han establecido tal debate, lo hayan hecho a diferentes niveles: casi la mitad de ellos lo hacen a un nivel más formal (en el Consejo Escolar o en una comisión creada al efecto), y algo más de la mitad lo hace a niveles más informales (entre personas de la comunidad educativa interesadas en el tema o en reuniones de los diferentes colectivos de la misma).

En la Segunda Parte del Cuestionario destacamos que la mayor parte de escuelas (86\%) programa actividades curriculares en relación a la educación ambiental y el desarrollo sostenible (frente a tan sólo un 11,3\% que no realiza actividades de este tipo), bien como tema transversal $(55,3 \%)$, o como parte del contenido de algún área curricular (50\%); siendo estadísticamente significativo que entre los centros que la incluyen como tema transversal está el más alto porcentaje de aquellos que disponen de una política ambiental reflejada en documentos oficiales del centro $(62,5 \%)$ :

\section{CUADro 6}

Inclusión de actividades en las programaciones de aula

\begin{tabular}{|c|c|c|c|c|c|c|c|c|c|c|c|}
\hline & \multirow[b]{2}{*}{ Total } & \multicolumn{2}{|c|}{ Polít. ambien. } & \multicolumn{2}{|c|}{ En prog. } & \multicolumn{2}{|c|}{ Municipios } & \multicolumn{4}{|c|}{ № de habitantes } \\
\hline & & $\begin{array}{c}\text { Sí } \\
\text { reflej. } \\
\text { en } \\
\text { docu. }\end{array}$ & $\begin{array}{c}\text { No } \\
\text { dispone }\end{array}$ & Sí & No & $\begin{array}{c}\text { Con } \\
\text { Agenda } \\
21\end{array}$ & $\begin{array}{c}\operatorname{Sin} \\
\text { Agenda } \\
21\end{array}$ & $\begin{array}{l}\text { Hasta } \\
1.000\end{array}$ & $\begin{array}{c}1.001 \\
a 10.000\end{array}$ & $\begin{array}{l}10.001 \mathrm{a} \\
100.000\end{array}$ & $\begin{array}{c}+ \text { de } \\
500.000\end{array}$ \\
\hline Total & 150 & 104 & 31 & 129 & 17 & 58 & 92 & 10 & 50 & 75 & 15 \\
\hline Si & 86 & 89,4 & 80,6 & 100 & - & 87,9 & 84,8 & 80 & 88 & 88 & 73,3 \\
\hline - Si, como transversal & 55.3 & 62,5 & 35,5 & 64,3 & - & 55,2 & 55,4 & 40 & 56 & 58,7 & 46,7 \\
\hline - Sí, parte de contenido de área & 50 & 51 & 51,6 & 58,1 & - & 50 & 50 & 40 & 50 & 53,3 & 40 \\
\hline No & 11,3 & 6,7 & 19,4 & - & 100 & 10,3 & 12 & 10 & 10 & 9,3 & 26,7 \\
\hline $\mathrm{Ns} / \mathrm{nc}$ & 2,7 & 3,8 & - & - & - & 1,7 & 3,3 & 10 & 2 & 2.7 & - \\
\hline
\end{tabular}

Casi el 90\% de los centros realizan actividades extracurriculares complementarias relacionadas con el desarrollo sostenible, como las referidas a la paz $(74,7 \%)$; 
la protección del medio ambiente (46\%), tales como la recogida selectiva de residuos para reciclar, campañas de ahorro de energía y recursos naturales - agua, luz, gas--, prevención de incendios, concienciación sobre la emisión de gases contaminantes o transporte sano; la plantación de árboles o el mantenimiento de huertos o jardines $(70,7 \%)$; la solidaridad, igualdad por razón de sexo, etnia o cultura, prevención de la delincuencia, resolución de conflictos o educación para la salud:

CuAdro 7

Actividades extra-curriculares complementarias

\begin{tabular}{|c|c|c|c|c|c|c|c|c|c|c|c|}
\hline & \multirow[b]{2}{*}{ Total } & \multicolumn{2}{|c|}{ Polít. ambien. } & \multicolumn{2}{|c|}{ En prog. } & \multicolumn{2}{|c|}{ Municipios } & \multicolumn{4}{|c|}{ № de habitantes } \\
\hline & & $\begin{array}{c}\text { Sí } \\
\text { reflej. } \\
\text { en } \\
\text { docu. }\end{array}$ & $\begin{array}{c}\text { No } \\
\text { dispone }\end{array}$ & $\overline{\mathrm{Si}}$ & No & $\begin{array}{c}\text { Con } \\
\text { Agenda } \\
21\end{array}$ & $\begin{array}{c}\text { Sin } \\
\text { Agenda } \\
21\end{array}$ & $\begin{array}{l}\text { Hasta } \\
1.000\end{array}$ & $\begin{array}{c}1.001 \\
a 10.000\end{array}$ & $\begin{array}{l}10.001 \mathrm{a} \\
100.000\end{array}$ & $\begin{array}{c}+ \text { de } \\
500.000\end{array}$ \\
\hline Total & 150 & 104 & 31 & 129 & 17 & 58 & 92 & 10 & 50 & 75 & 15 \\
\hline Día/semana de la paz & 74,7 & 71,2 & 80.6 & 74,4 & 76,5 & 63,8 & 81,5 & 90 & 76 & 73.3 & 66.7 \\
\hline Día/semana solidaridad & 38,7 & 43,3 & 29 & 41,1 & 23,5 & 39,7 & 38 & 20 & 34 & 46,7 & 26,7 \\
\hline Día/semana medio ambiente & 46 & 51,9 & 29 & 48,1 & 23,5 & 48,3 & 44,6 & 60 & 44 & 52 & 13,3 \\
\hline Día/semana de la salud & 3,3 & 4,8 & - & 3,9 & - & 6,9 & 1,1 & - & - & 6,7 & - \\
\hline Semana cultural & 8 & 7,7 & 6,5 & 7,8 & 5,9 & 12,1 & 5,4 & 10 & 4 & 9,3 & 13,3 \\
\hline Día del árbol & 70,7 & 71,2 & 74,2 & 72,9 & 58,8 & 62,1 & 76,1 & 80 & 76 & 74,7 & 26,7 \\
\hline Varios & 9,3 & 11,5 & 3,2 & 8,5 & 11,8 & 19 & 3,3 & 10 & 8 & 8 & 20 \\
\hline No contestan & 7,3 & 6,7 & 9,7 & 7 & 11,8 & 8,6 & 6,5 & - & 6 & 6,7 & 20 \\
\hline Ns & 1,3 & 1 & 3,2 & 1,6 & - & 1,7 & 1,1 & - & 2 & 1,3 & - \\
\hline
\end{tabular}

Entre el $62,7 \%$ de centros que no han recibido ayudas o subvenciones para proyectos medioambientales se encuentran los centros ubicados en los municipios de tamaño mayor de habitantes (100\%) y más pequeños (70\%) y en los cuales se encuentran los que mayoritariamente no disponen de una política ambiental reflejada en documentos oficiales $(83,9 \%)$. Son muy pocos los centros que han recibido ayudas de instituciones privadas (3,3\%); siendo considerable el porcentaje de aquellos que han recibido este tipo de ayudas por parte de las instituciones públicas $(36,7 \%)$ constatándose la misma tendencia de ser éstas las que disponen de una política ambiental reflejada en documentos oficiales $(44,2 \%)$ : 


\section{CUADRO 8}

Ayudas o subvenciones para proyectos medio-ambientales

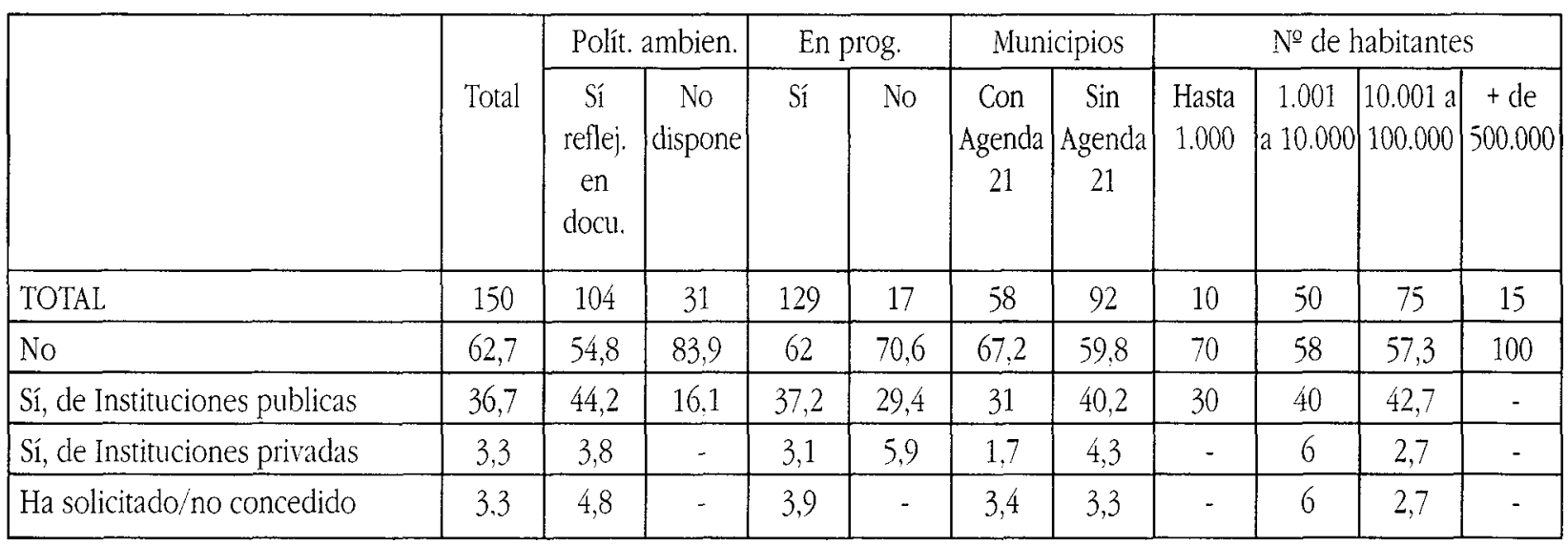

La cuarta parte de los centros de la muestra no realiza actuaciones conjuntas en relación a la educación ambiental y el desarrollo sostenible, siendo significativo que entre ellos estén, de forma mayoritaria, los centros que no disponen de política ambiental reflejada en documentos oficiales (48,45\%), los que no incluyen actividades de este tipo en sus programaciones de aula (20,9\%), y los que están ubicados en un porcentaje mayor, aunque no estadísticamente significativo, en municipios de población extrema (o muy grandes o muy pequeños). Existe un porcentaje menor de centros que realiza actuaciones conjuntas con otros centros (10\%). Pero existe un mayor porcentaje en nuestra muestra de estudio que realiza actuaciones conjuntas en materia de educación ambiental y desarrollo sostenible entre profesores y alumnos $(51,3 \%)$, entre profesores de diferentes materias $(41,3 \%)$, y entre profesores y AMPA (21,3\%), siendo estadísticamente significativo que entre todos ellos existe un porcentaje mayor de centros que disponen de una política ambiental reflejada en documentos oficiales; y es también estadísticamente reseñable que entre los centros que realizan actividades conjuntas entre profesores y alumnos se encuentre una mayor proporción de centros $(56,6 \%)$ que incluye dichas actuaciones conjuntas en sus programaciones de aula: 
CUADRO 9

Actuaciones conjuntas

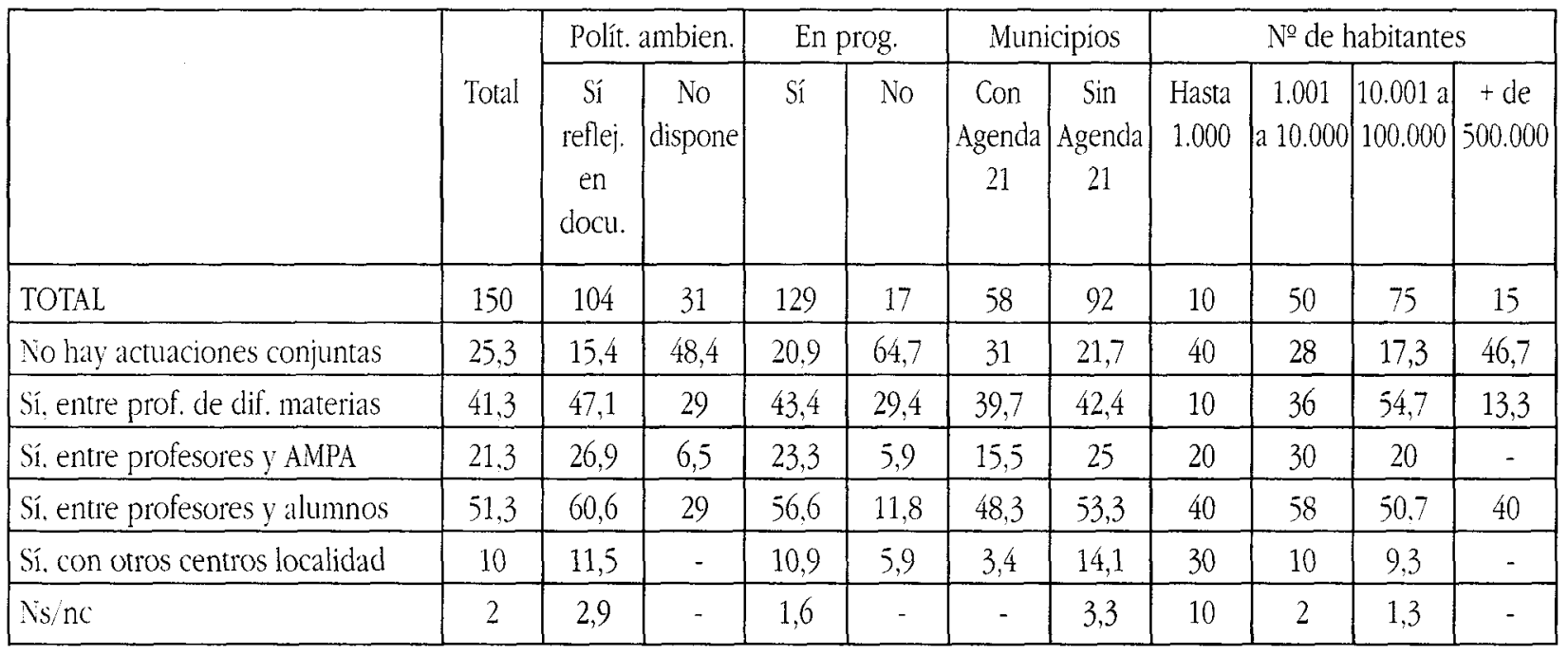

El 70\% de los centros no ha realizado ni está realizando ninguna ecoauditoría educativa integrada en el currículum, aunque el 18,7\% considera que debería realizarla. Sólo el $2 \%$ de centros la ha realizado como parte del contenido curricular, y el $6 \%$ la ha realizado como actividad complementaria; observándose la misma tendencia anteriormente apuntada.

CuAdro 10

Ecoauditoría educativa integrada en el currículum

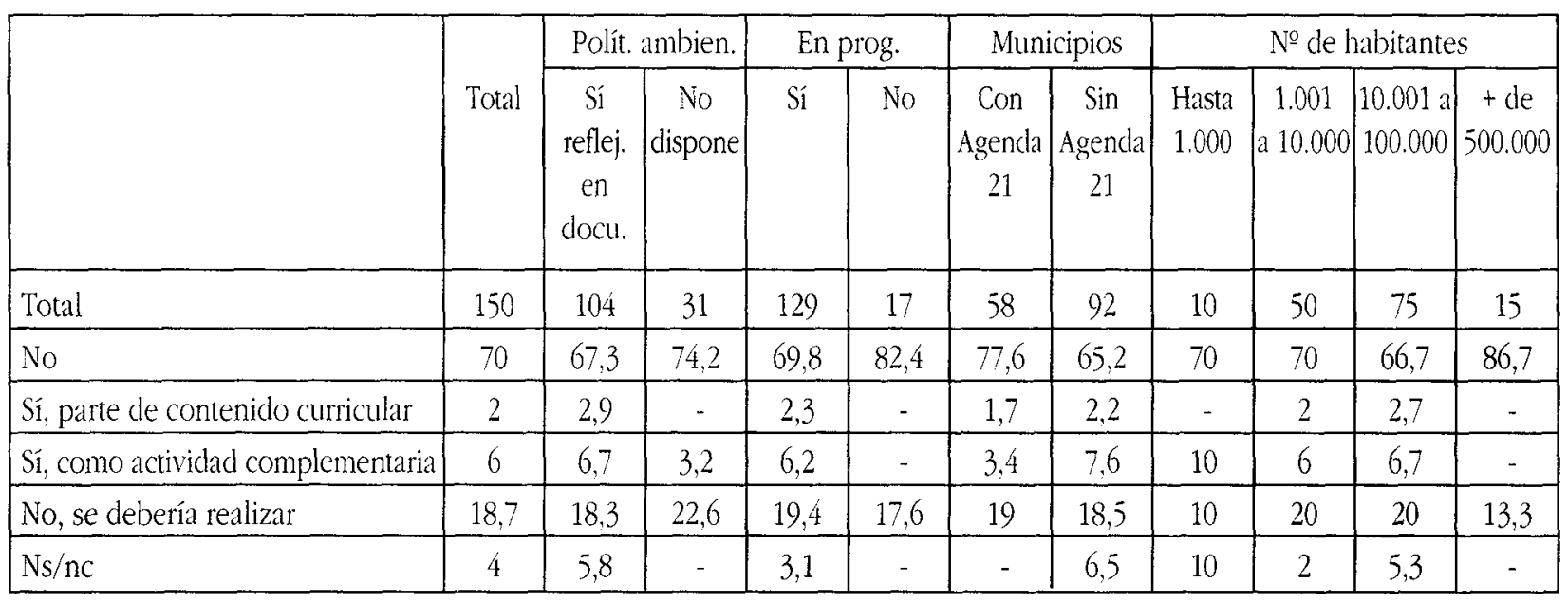

En la Tercera Parte del Cuestionario encontramos que sólo el 10,7\% de centros educativos tiene algún tipo de información acerca de lo que es una Agenda 21 local, entre los cuales se encuentra un porcentaje significativo mayor de centros que están ubicados en municipios que están implantando una Agenda 21 local (19\%); el 15,3\% dispone de una información vaga; pero la mayoría de centros desconoce su significado $(72,7 \%)$, de entre los cuales se encuentran en mayor 
proporción significativa los centros ubicados en municipios que no han iniciado procesos de sostenibilidad (79,35\%).

Ratificamos aquí también la tendencia a que los centros que conocen el significado de lo que representa implantar una Agenda 21 local sean los centros que disponen de una política ambiental e incluyen en sus programaciones de aula actividades relacionadas con la educación ambiental y el desarrollo sostenible.

CuAdro 11

Información sobre la Agenda 21 local

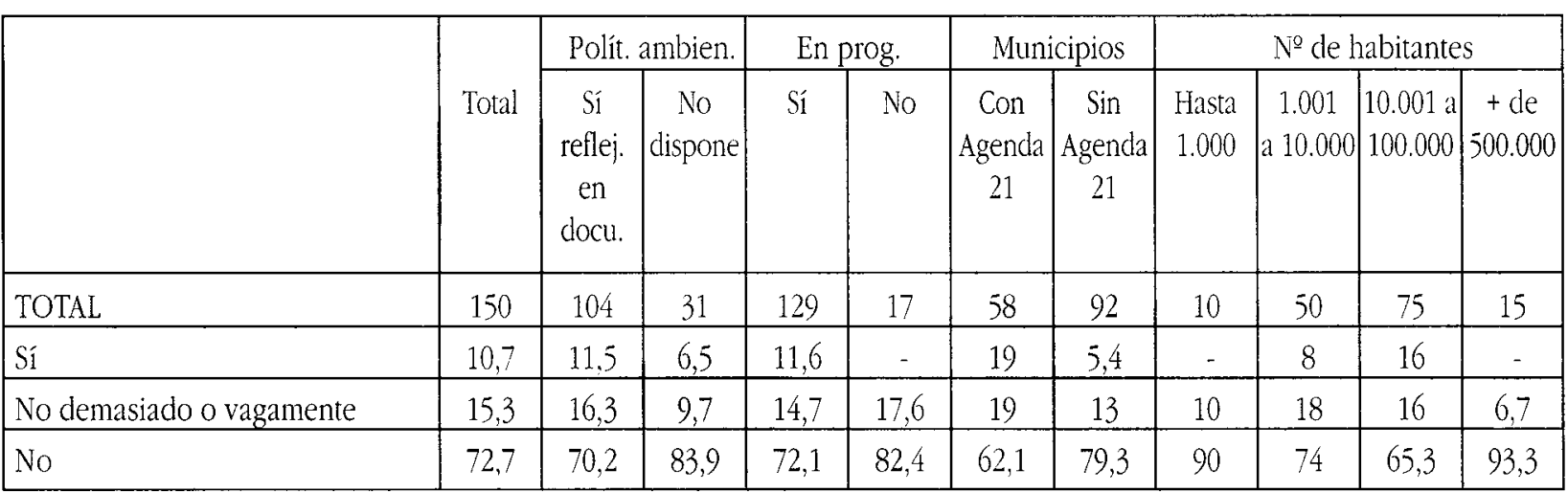

Existe un desconocimiento generalizado en los centros educativos de la muestra en relación a estas cuestiones, pudiendo comprobar la coherencia de la proporción de centros educativos que tienen información sobre la implantación y desarrollo de la Agenda 21 en el municipio donde están ubicadas $(10,7 \%)$ con el mismo porcentaje de centros que conoce el significado de lo que es una Agenda 21 local y su ubicación en municipios que han iniciado su implantación (20,7\%). Aunque cabe subrayar el desconocimiento de este hecho por parte del mayor número de escuelas $(74,7 \%)$ :

CUADRO 12

Información sobre la implantación de la Agenda 21 local

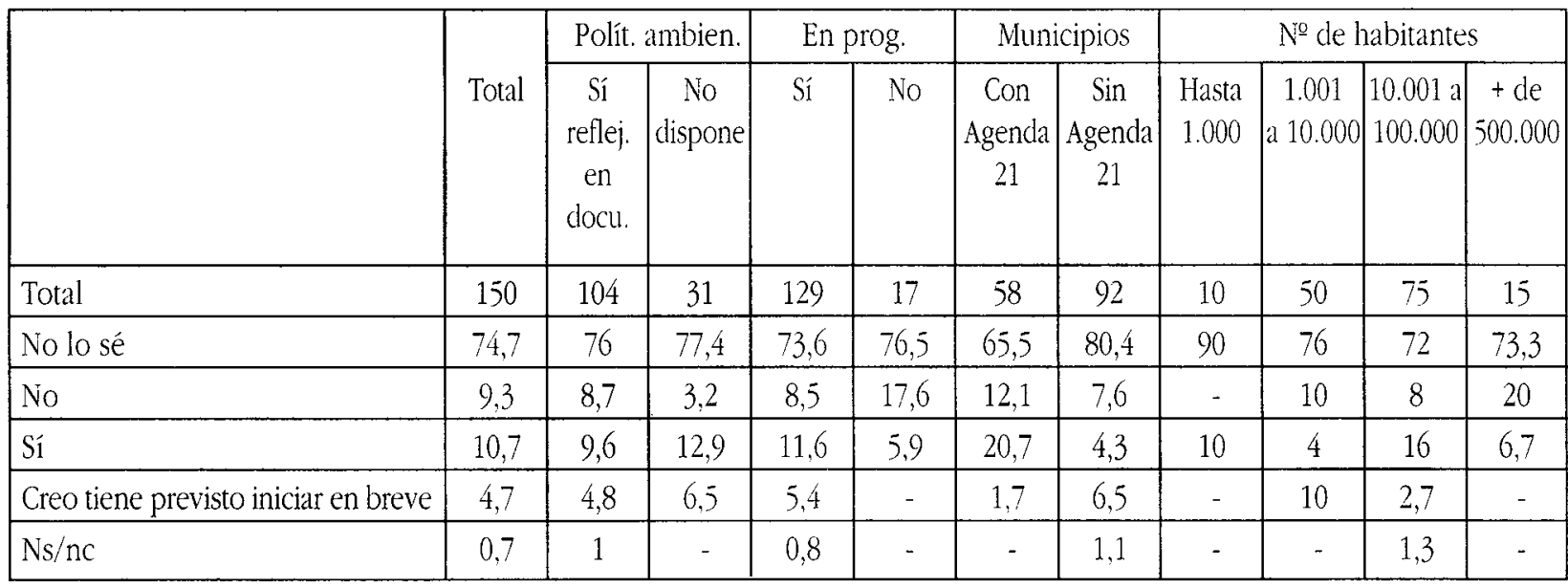


La misma tendencia de respuesta se observa respecto a la información disponible en las escuelas sobre el foro de participación ciudadana y la propia posibilidad de participación de la comunidad educativa en dichos foros. Si bien algo más de un tercio de escuelas confiesa estar dispuesta a participar en los mismos para impulsar el desarrollo sostenible local, y otro tercio podría estarlo, aunque con dificultades.

Entre las posibles acciones a realizar en la escuela para contribuir al desarrollo sostenible de la localidad en la que está ubicada, los encuestados han formulado un abanico relativamente amplio de propuestas que, por la índole abierta en la que se formuló este ítem, hemos categorizado del modo que sigue:

\section{CUADRO 13}

Posibles acciones a realizar en el centro educativo

\begin{tabular}{|c|c|c|c|c|c|c|c|c|c|c|c|}
\hline & \multirow[b]{2}{*}{ Total } & \multicolumn{2}{|c|}{ Polit. ambien. } & \multicolumn{2}{|c|}{ En prog. } & \multicolumn{2}{|c|}{ Municipios } & \multicolumn{4}{|c|}{$N^{0}$ de habitantes } \\
\hline & & $\begin{array}{c}\text { Si } \\
\text { reflej. } \\
\text { en } \\
\text { docu. }\end{array}$ & $\begin{array}{c}\text { No } \\
\text { dispone }\end{array}$ & Sí & No & $\begin{array}{c}\text { Con } \\
\text { Agenda } \\
21\end{array}$ & $\begin{array}{c}\text { Sin } \\
\text { Agenda } \\
21\end{array}$ & $\begin{array}{l}\text { Hasta } \\
1.000\end{array}$ & $\begin{array}{c}1.001 \\
10.000\end{array}$ & $\begin{array}{l}10.001 \mathrm{a} \\
100.000\end{array}$ & $\begin{array}{c}+ \text { de } \\
500.000\end{array}$ \\
\hline Total & 150 & 104 & 31 & 129 & 17 & 58 & 92 & 10 & 50 & 75 & 15 \\
\hline Tall. reutilización/reciclaje & 18 & 19,2 & 6,5 & 20,2 & 5,9 & 19 & 17,4 & 20 & 16 & 20 & 13,3 \\
\hline Implicar a todos los estamentos & 29,3 & 29,8 & 32,3 & 32,6 & 11,8 & 25.9 & 31,5 & 20 & 36 & 24 & 40 \\
\hline Disminución consumo/uso recursos & 11,3 & 9,6 & 9,7 & 13,2 & - & 12,1 & 10,9 & 10 & 12 & 10,7 & 13,3 \\
\hline Campanas de solidaridad & 6 & 5,8 & 6,5 & 7 & - & 8,6 & 4,3 & - & 2 & 9,3 & 6,7 \\
\hline Prog. concienc./protección & 10,7 & 10,6 & 9,7 & 12,4 & - & 13,8 & 8,7 & 20 & 8 & 12 & 6,7 \\
\hline Colaboración centro/Admón. local & 2 & 2,9 & - & 1,6 & 5,9 & 3,4 & 1,1 & - & 2 & 2,7 & - \\
\hline Incluir en Proyecto Educativo & 13,3 & 13,5 & 16,1 & 14 & 11,8 & 24,1 & 6,5 & 10 & 14 & 13,3 & 13,3 \\
\hline Varios & 0,7 & 1 & - & 0,8 & - & - & 1,1 & - & - & 1,3 & - \\
\hline No contestan & 47,3 & 46,2 & 48,4 & 42,6 & 70,6 & 44,8 & 48,9 & 40 & 48 & 48 & 46,7 \\
\hline
\end{tabular}

Con una tasa de respuestas del $52,7 \%$, los centros educativos de la muestra proponen en primer lugar la implicación de todos los estamentos en la realización de acciones a favor del desarrollo sostenible (29,3\%), tales como: campañas informativas desde la Administración educativa y el Gobierno local, coordinación de los centros educativos del municipio con los organismos competentes, información/reciclaje del profesorado en cuestiones relacionadas con el desarrollo sostenible, implicación del Ayuntamiento en las actividades de la escuela, proyectos de trabajo sobre hábitos, actitudes y valores que impliquen a toda la comunidad educativa. La inclusión de las acciones a realizar en el PEC (13,3\%), tales como ecoauditorías educativas, contextualización de los programas educativos, colaboración de los equipamientos de educación ambiental, realización de programas para desarrollar la conciencia ecológica, realización de jornadas ambientales y diseño y aplicación de temas transversales. La realización de talleres de reutilización y reciclaje de residuos 
(18\%). El desarrollo de normativa consensuada para disminuir el uso o consumo de recursos $(11,3 \%)$ a través de campañas de ahorro de papel, de concienciación sobre el uso del agua, y de gestión para el ahorro de energía. La realización de programas de concienciación y protección de la biodiversidad (10,7\%), a través de la potenciación del "huerto escolar", el cuidado de vivarios, información sobre las consecuencias de las aguas contaminadas por las empresas locales, o sobre la deforestación por innovaciones de tierras. La realización de campañas de solidaridad $(6 \%)$, a través de la colaboración con otros centros educativos de la localidad en la realización de actividades solidarias, la realización de programas educativos para fomentar la tolerancia, la convivencia intercultural y el consumo responsable

\section{CONCLUSIONES}

La caracterización de los centros educativos en relación al tema de nuestro estudio realizada en nuestro análisis nos puede llevar a conclusiones que podrían ser más precisas si atendemos a las características establecidas, no sólo en razón de los rasgos que permiten diferenciar a unos centros de otros, sino también en razón de los rasgos comunes a todos ellos. En este sentido detectamos que la proporción de municipios que ha implantado o está implantando una Agenda 21 local es similar en el conjunto de los centros, no siendo significativa la diferencia que presentan éstos por el hecho de estar ubicados en tales municipios. La falta de relación encontrada entre municipios con proyectos de sostenibilidad y escuelas con prácticas relacionadas con el desarrollo sostenible indica una ausencia de interacción entre las administraciones locales y las agencias educativas formales del municipio. De igual modo parece no tener influencia las etapas que se desarrollan en una escuela, con el hecho de que la escuela reúna las características mayormente definidoras de una institución educativa en la que se propicia la sostenibilidad del desarrollo; más bien parece lógico que todo tipo de escuela, de enseñanza primaria o secundaria es una institución idónea para desarrollar acciones compatibles con el desarrollo sostenible. Así mismo podemos concluir que las escuelas ubicadas en poblaciones de tamaño mediano presentan una mayor tendencia hacia el desarrollo sostenible que las escuelas ubicadas en poblaciones de tamaño muy pequeño o muy grande; lo cual nos lleva a alertar sobre la necesidad de variar las estrategias de intervención en función de este hecho

La reflexión sobre los resultados obtenidos nos lleva a precisar una serie de aspectos en forma de conclusiones específicas que consideramos debería conformar la plataforma de base desde la que comenzar a gestar lo que puede ser una escuela sostenible o el desarrollo de una Agenda 21 para las escuelas:

1) En primer lugar, el hecho de que la mayor parte de los centros disponga de una política ambiental expresada de manera formal referida a programas, actividades curriculares y normativa de acción relacionada con la educación ambiental y considerando que el medio ambiente incluye no sólo aspectos 
ecológicos, sino también económicos, sociales, y éticos representa un hecho facilitador para iniciar procesos de sostenibilidad escolar.

$\left.2^{\circ}\right)$ En segundo lugar, podemos afirmar, sin embargo, que no existe una cultura de la sostenibilidad generalizada en nuestras escuelas; aunque se puede hablar de una cultura incipiente, en unos centros más que en otros, hacia la educación ambiental, la educación para la paz, la educación intercultural, o la educación para la salud. Pero aunque el papel de la escuela en el desarrollo sostenible de la comunidad local en la que está inserta es clave, no existe, en general, una escuela bien informada al respecto. Esto representa una entre las varias paradojas instaladas en la escuela de hoy que: a) tiene que enfrentarse a las exigencias de las nuevas tecnologías de la información y de la comunicación sin ser engullida por ellas; b) tiene que enfrentarse a la globalización y uniformización cultural sin obviar y proteger la cultura local; y c) tiene que atender al desarrollo de valores esenciales en climas que están siendo de conflicto y violencia.

$3^{\text {o) }}$ En tercer lugar, consideramos como condición indispensable la realización de acciones de información, reciclaje, participación y formación, como una "tasa" IRPF para el desarrollo sostenible; por una parte, la información y la creación de condiciones para la participación, como responsabilidad prioritaria de las administraciones locales; y por otra, el reciclaje y la formación para las nuevas estrategias de una acción educativa innovadora, como responsabilidad de las administraciones educativas autonómicas y municipales con el apoyo de servicios educativos especializados.

$4^{\circ}$ ) Igualmente concluimos la necesidad de modificar el tratamiento atomista que reciben los contenidos relacionados con el desarrollo sostenible en nuestras escuelas, por un tratamiento sistémico, globalizador e integrador de nuevas propuestas que atiendan todos los aspectos involucrados en el desarrollo humano sostenible, desde objetivos unitarios y enfoques holísticos, y que propicien un cuestionamiento crítico de la multitransversalidad y la búsqueda de alternativas más eficaces.

5) Cualquier propuesta de "educación" para el desarrollo humano sostenible no puede obviar las "prácticas sostenibles" en el comportamiento cotidiano de la escuela; lo cual reclama también propuestas educativas relativas a la gestión de recursos desde criterios normativos de sostenibilidad.

$\left.6^{\circ}\right)$ Por otra parte, el hecho de que nuestras escuelas no dispongan de "referentes" desde los que diferenciar las formas sostenibles de las no sostenibles del desarrollo en los diferentes aspectos que constituyen la vida escolar, hace requerible la construcción de sistemas de indicadores; ya que el desarrollo humano sostenible se ha de concebir, desde la educación, como un proceso permanente que requiere ser evaluado desde parámetros establecidos en base a decisiones pedagógicas para comprobar si tal desarrollo avanza o retrocede hacia la sostenibilidad. 
$7^{\circ}$ ) Finalmente concluimos que, junto a una implementación de la estructura social Interna de participación de la comunidad educativa en los diferentes órganos colegiados desde los que se toman decisiones que afectan a todos, habría que construir una estructura social externa de participación en el desarrollo de planes de sostenibilidad para el municipio donde transcurren sus vidas. Una estructura que pudiera facilitar interacciones entre la comunidad educativa y los agentes políticos y sociales del municipio; que fuera suscitadora de debates, propiciara consensos y en la que se pudiera canalizar una toma de decisiones acordes con las exigencias de un desarrollo humano sostenible.

Creemos que la escuela debería asomarse a esta otra estructura más amplia y extraescolar de participación, y capacitar a los sujetos en formación, para integrarse en ella (Subirats i Humet, 2002). Y, aunque la escuela ya cuenta con una estructura interna de participación que puede facilitar la implicación de la comunidad educativa en el desarrollo sostenible a nivel local que se quiere conseguir, haría falta poner en marcha mecanismos de interacción con estructuras de participación extraescolar, mediante estrategias que impliquen grados diversos de menor a mayor implicación social:

a) Desde una implicación social de nivel puramente informativo; por ejemplo, con la constitución en el Foro Escolar de un Comité de Información que desarrollara diversos procedimientos para mantener informada a la comunidad educativa (paneles informativos, radio escolar, boletín de noticias, asambleas...).

b) Una implicación social de nivel consultivo, dinamizada a través de la constitución de un Consejo Consultivo para la sostenibilidad con la inclusión de órganos unipersonales ajenos a la escuela (Ayuntamiento, ONGs...).

c) Una implicación social de nivel decisorio, en el cual la participación ya va asociada al concepto de cambio y requiere niveles de información más completa y niveles de formación más específica para comparar alternativas al curso de una acción y sus posibles consecuencias.

d) Una implicación social de nivel operativo que fuerza la participación en la puesta en práctica y seguimiento de los planes de acción.

La última edición del Análisis sobre Política Educativa de la OCDE de $2001^{20}$ cuestiona si la escuela, tal como la conocemos ahora, seguirá existiendo o será sustituida por estructuras educativas alternativas más acordes con las necesidades de la formación continua y con los cambios exigidos por la sociedad del conocimiento. Pero sea cual fuere el tipo de escuela del futuro, no podemos evadir la reconsideración de su valor dentro del contexto social local en el que se inserta

20. Debatida en la reunión de Ministros de la OCDE los días 2 al 4 de abril de 2001 en París. OCDE (2001) Análisis de las políticas de educación. Madrid, Mundi Prensa Libros. 
desde planteamientos coherentes con las nuevas exigencias sociales, entre las que el desarrollo humano sostenible es una cuestión que encierra un imperativo moral.

La crisis global del planeta ya no es una tesis mantenida por unas minorías; es una constatación compartida por científicos, políticos y grupos sociales. El cambio que requiere la búsqueda de soluciones a los problemas generados implica a la propia forma y estilo de vida de todos los habitantes del planeta; e implica a la escuela por su influencia en el replanteamiento sobre la forma en que los seres humanos nos relacionamos con el mundo que nos rodea; nuestras actitudes respecto al entorno y la forma en que desarrollamos nuestras relaciones entre grupos sociales y países (primer, tercer y cuarto mundo) son el resultado de unas preconcepciones que se explicitan en valores y criterios que aplicamos al actuar.

Es necesario identificar las prácticas que no son sostenibles e investigar las posibilidades de corregirlas, empezando por una difusión adecuada del significado del desarrollo sostenible y de un debate para fomentar la comprensión y obtener el apoyo de la comunidad en todos los contextos comunitarios y en todas las instituciones, incluidas las instituciones de enseñanza (Comisión para el Desarrollo Sostenible de Naciones Unidas, 1997, 46).

Desde la construcción de una Escuela 21 o desde la Agenda 21 escolar se ha de pretender replantear los viejos valores que han propiciado la crisis global del planeta y fundamentar sus acciones en una ética que posibilite la evolución desde una cultura y estilos de vida que se han venido definiendo como insostenibles, a otros que se presenten como alternativa haciendo compatibles calidad de vida y desarrollo humano sostenible. Y éstos son cambios que implican compartir la responsabilidad a escala mundial, comunitaria, regional, local e incluso personal.

La escuela no es únicamente un espacio de formación; es también un lugar de experimentación de nuevas propuestas educativas, y una plataforma de difusión de cambios en las percepciones, actitudes y comportamientos hacia nuevas formas de vida más sostenibles. El marco de referencia normativo actual con el que se cuenta, creemos es válido; aunque nos encontramos con un debate profundo sobre los contenidos y las competencias básicas a definir en los diferentes niveles de la enseñanza, así como sobre la redefinición de la transversalidad, que ante la puesta en marcha de la nueva Ley de Calidad, puede verse afectada. 


\section{Bibliografía}

AA.VV. (1999) La educación en el siglo XXI. Los retos del futuro inmediato. Barcelona, Graó.

- (1999) Los valores en la Europa del siglo XXI. Actas XXXIII Coloquio de Inspectores Europeos de Educación y I Jornada Europea de Educación. Valencia. Edit. ADEP.

ANDer-EgG, E. (1996) Participación ciudadana y protagonismo de la sociedad civil, Ciclos, 1.

Almenar, R. y Diago Giraldos, M. (2002) El Proyecto necesario. Construir un desarrollo sostenible a escala regional y local. Valencia, Patronat Sud.Nord de la Fundació General de la Universitat de València i Publicacions de la Universitat de València. La Nau Solidaria.

Apple, K. O. (1993) La crise ecologique en tant que prolème pour l'éthique du discours, en HotTois, G. y Pinsart (eds.). Hans Jonas. Nature et responsabilité. París, Vrin.

- (1999) Globalización y la necesidad de una ética universal, Debats, 66.

AZnar Minguet, P. (2000) Bienestar y desarrollo humano sostenible: retos educativos a nivel local. Addenda presentada al XIX Seminario Interuniversitario de Teoría de la Educación. El Escorial (Madrid).

- (2003) Educación ambiental y desarrollo sostenible. Hacia la construcción de la Agenda 21 escolar, en Mangas, V. J. Educación ambiental y sostenibilidad. Alicante, Ediciones Universidad de Alicante/CAM, 53-78.

Aznar Minguet, P. y Zabala, J. (1999) Educación y desarrollo humano sostenible, en RodríGuez NeIRA, T. et al. Cambio educativo: presente y futuro. Oviedo, Ediciones de la Universidad de Oviedo.

BANCo Mundial (2001) Informe sobre el desarrollo mundial: lucha contra la pobreza. Madrid, Mundi Prensa Libros.

BisquerRa, R. (1989) Introducción conceptual al análisis multivariable, vols. I y II. Barcelona, PPU. S.A.

Bunge, M. (1989) Mente y sociedad. Madrid, Alianza-Universidad.

BRUndtland, G. H. (1988) Nuestro futuro común. Madrid, Alianza.

Colom CAÑellas, A. J. (2000) Desarrollo sostenible y educación para el desarrollo. Barcelona, Octaedro.

COMISIÓN PARA el DeSARROllo SOSTENible (1997) Educación para un futuro sostenible; una visión transdisciplinaria para una acción cencertada. Conferencia Internacional sobre medio Ambiente y Sociedad: educación y sensibilidad en materia de sostenibilidad. Tesalónica, ONU. EPD-97/CONF.401/CLD.1.

COMISIÓN DE LAS COMUNIDADES EUROPEAS (1994) Urban European Indicators Program. European Institut for the urban environment. Luxemburgo, Oficina de Publicaciones de las Comunidades Europeas.

Escámez, J. y GiL, R. (2001) La educación en la responsabilidad. Barcelona, Paidós.

Goodland, R. et al. (1997) Medio Ambiente y Desarrollo Sostenible. Madrid, Trotta.

Habermas, J. (1989) Teoría de la acción comunicativa. Complementos y estudios previos. Madrid, Cátedra.

HewrtT, N. (1998) Guía Europea para la planificación de las Agendas 21 locales. Cómo implicarse en un plan de acción ambiental a largo plazo bacia la sostenibilidad. Bilbao, Editorial Bakeaz, Guildford.

JoNAS, H. (1995) El principio de responsabilidad. Ensayo de una ética para la civilización tecnológica. Barcelona, Herder.

López-Barajas, E. y Ruiz Corbella, M. (coord.) (2000) Derechos bumanos y educación Madrid, UNED. 
Manzini, E. (1992) Artefactos. Hacia una nueva ecología del ambiente artificial. Madrid, Celeste Ediciones.

Martín Sosa, N. (1994) Ética ecológica. Madrid, Libertas.

- (1997) El qué y el para qué de una ética ecológica. Valsaín, Segovia, Carpeta Informativa del CENEAM.

Meadows, D. H.; Meadows, D. L. y Randers, J. (1993) Más allá de los limites del crecimiento Madrid, País-Aguilar.

Meadows, D. H.; Meadows, D. L.; Randers, J. y Beherens, E. (1972) Los limites del crecimiento. Informe del Club de Roma. México, FCE.

Ministerio de MEDio AMBIENTE (1997) Educación para el desarrollo sostenible. Documentos Internacionales. Los Documentos de Rio: Declaración de Principios. La Agenda 21. Madrid, Centro de Publicaciones de la Secretaría General de Medio Ambiente.

- Educación para el Desarrollo Sostenible. Documentos Internacionales: El V Programa: para un Desarrollo Sostenible. Madrid, Secretaría General de Medio Ambiente.

Morín, E. (1984) Ciencia con conciencia. Barcelona, Antrhophos.

OCDE (2001) Análisis de las políticas de educación. Madrid, Mundi Prensa Libros.

PNUD (2001) Informe sobre el Desarrollo Humano. Poner el adelanto tecnológico al servicio del desarrollo. Madrid, Unesco/Mundi Prensa Libro.

Rodríguez NeIRA, T. (1999) La cultura contra la escuela. Barcelona, Ariel.

SANPEDRo, J. L. (1982) El desarrollo: dimensión patológica de la cultura industrial, Desarrollo, 1.

Subirats i Humet, J. (2002) Gobierno local y educación. La importancia del territorio y la comunidad en el papel de la escuela. Barcelona, Ariel.

TOU RINÁn LóPEZ, J. M. (1999) Globalización, desarrollo y política regional, en ORTEGa, P. y Mínglez, R. Educación, cooperación y desarrollo. Murcia, Ediciones Caja/Murcia Obra Cultural, 35-68.

UNESCO (1998) La Educación Superior y el desarrollo humano sostenible, en La Educación Superior en el siglo XXI. Visión y acción. París, Conferencia Mundial sobre la Educación Superior. ED 98/CONF 202/7.2

\section{WEB SITES}

Asociación Europea de ciudades sostenibles, wwww.sustainable-cities.org/expert.html.

Consejo de la Tierra, www.ecouncil.ac.ar/rio.

The International Council for Local Environmental Initiatives, www.ICLEI.org/.

El estado del mundo, www.worldwatch.org/.

Federación Española de Municipios y Provincias, www.femp.es.

Guía Europea para la planificación de las Agendas 21 locales, www.mma.es: 8088/ CDMMA/Ceneam/05Bibliografia/biblio50.htm.

Indicadores de desarrollo sostenible, www.un.org/sustdev/isd.htm.

Sustainability-The Aarlborg Declaration and Agenda 21 on a local level. 


\section{ANEXO 1 \\ Cuestionario}

La Agenda 21 local y la sostenibilidad del desarrollo: participación de las agencias educativas formales

Este cuestionario se dirige a los centros educativos formales de enseñanza primaria. Las preguntas planteadas pretenden reflejar aspectos sobre el clesarrollo sostenible, la gestión y la educación ambiental del centro, y su posible participación en el proceso de implantación y desarrollo de la Agenda 21 local en el municipio.

A pesar del formato cerrado de la mayor parte de las preguntas, tiene usted plena libertad para acompañar sus respuestas de comentarios o anexos que ayuden a proporcionar una información más exacta y significativa.

La información que nos suministren va a representar la base de una investigación evolutiva sobre la participación de la educación formal en la sostenibilidad del desarrollo a nivel local. Su colaboración en la presente investigación es muy importante.

El cuestionario se dirige al director del centro educativo o persona en quien delegue.

\section{Datos de identificación}

01. Nombre del centro educativo

02. Código

03. Etapas educativas que se imparten en el centro:

$\begin{array}{ll}1 \supseteq \text { Infantil } & 4 \supseteq \text { Bachiller } \\ 2 \supseteq \text { (Primaria } & 5 \supseteq \text { Formación Profesional } \\ 3 \supseteq \text { Sencundaria } & \end{array}$

04. № de alumnos que tiene el centro:

05. Nombre del municipio

06. № de habitantes del municipio:

$\begin{array}{ll}1 \supseteq \text { Menos de mil habitantes } & 3 \supseteq \text { Entre } 10.001 \text { y } 100.000 \\ 2 \supseteq \text { Entre } 1.001 \text { y } 10.000 & 4 \supseteq \text { Más de } 500.000\end{array}$

07. Municipio en proceso de implantación de Agenda 21 Local:

$1 \supseteq \mathrm{Si}_{1}$

$2 \supseteq$ No

A. Política ambiental y desarrollo sostenible en el centro

Nota: Por política ambiental nos referimos a programas, actividades curriculares y normativas relacionadas con la protección, control, gestión y educación ambiental. Partimos de la consideración de que el medio ambiente incluye aspectos ecológicos, económicos, culturales, sociales o humanos y éticos. 
1. El centro dispone de una política ambiental reflejada en:

$1 \supseteq$ No queda reflejada en ningún documento

$2 \supseteq$ Las Actas del Consejo escolar

$3 \supseteq$ Proyecto Educativo de Centro

$4 \supseteq$ PGA (Plan General Anual)

$5 \supseteq$ No dispone de una política de gestión ambiental explícita

2. ¿En qué acciones se operativiza la política ambiental del centro?

$1 \supseteq$ En actividades curriculares sistemáticas

$2 \supseteq$ En actividades curriculares complementarias esporádicas

$3 \supseteq$ En la gestión de recursos (luz, agua, material fungible...)

$4 \supseteq$ Otros (especificar)

3. En el Centro ėexisten normas de actuación explícitas consensuadas por la comunidad educativa, en relación con la protección, control y gestión de aspectos ambientales?

$1 \supseteq S i ́$, existen normas explícitas y consensuadas

$2 \supseteq$ Sí, existen normas explícitas, pero no consensuadas

$3 \supseteq$ No existen normas explícitas

4. ¿Qué tipo de organismo desarrolla la política ambiental del centro?

$1 \supseteq$ El Equipo Directivo del centro

$2 \supseteq$ Departamento de Ciencias

$3 \supseteq$ El Consejo Escolar

$4 \supseteq$ Departamento de Sociales

$5 \supseteq$ La Comisión delegada de medio ambiente del centro

$6 \supseteq$ Otros (especificar)

5. Las decisiones que se toman en el centro (Consejo Escolar, Claustro...) itienen en cuenta criterios ambientales?

$1 \supseteq$ Sí, siempre, en todas las decisiones de los órganos colegiados del centro

$2 \supseteq$ A veces; en algunos aspectos

$3 \supseteq$ Nunca; no se tienen en cuenta

6. Marque el tipo de miembros unipersonales o colegiados que participan en actividades medioambientales en el centro (sean de enseñanza/aprendizaje, foros, comisiones consultivas...) y al mismo tiempo indique el grado de participación (Puntúe de 0 a 4: $0=$ No participan; 1 = participación poco significativa; 4 = participación muy significativa)

$1 \supseteq$ Nadie

2卫 Alumnos

$3 \supseteq$ Profesores

$4 \supseteq$ AMPA

$5 \supseteq$ PAS (personal de administración y servicios)

$6 \supseteq$ Responsable de la Administración local

7. ¿Se ha iniciado en el centro algún debate sobre el desarrollo sostenible o sobre la necesidad de adoptar políticas (estrategias, procedimientos...) de sostenibilidad para aplicarlas en el propio centro?

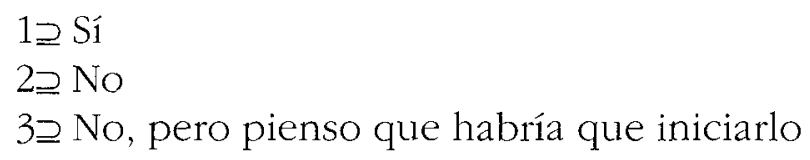


8. ¿A qué nivel se esta produciendo este debate?

$1 \supseteq$ En una comisión nombracla al efecto en el centro educativo

$2 \supseteq$ En el Consejo Escolar

3卫 Cada colectivo de manera separada (Claustro, AMPA...)

$4 \supseteq$ A nivel de personas de la comunidad educativa interesadas en el tema

9. De haberse producido o estar produciéndose el debate. éste queda reflejado en

$1 \supseteq$ Ningún clocumento; se trata cle un clebate informal

$2 \supseteq$ Las Actas del Consejo Escolar

$3 \supseteq$ Las Actas del Claustro

$4 \supseteq$ Las Actas de los clepartamentos

10. ¿De qué modo participan los alumnos en la política de sostenibilidad del centro?

$1 \supseteq$ A nivel de tutoría

$2 \supseteq$ En Comisión de alumnos

$3 \supseteq$ No existe participación de los alumnos

11. ¿Se ha iniciado en el centro algún clebate sobre su posible participación en el desarrollo sostenible del pueblo o ciudad (en la que el centro esta ubicado)?

$1 \supseteq$ Sí

$2 \supseteq$ No

$3 \supseteq$ No, pero considero que sería positivo iniciar un debate de ese tipo

12. El Consejo Escolar tha aprobado algún documento en el que la comunidad educativa muestre algún compromiso con el desarrollo sostenible?

$1 \supseteq$ No ha aprobado ningún documento que muestre ese compromiso

$2 \supseteq$ Sí, en el Proyecto Educativo

$3 \supseteq$ Sí, en la carta escolar de medio ambiente

$4 \supseteq$ Sí, en su adhesión al foro de participación ciudaclana del municipio.

13. ¿Ha diseñado el centro un modelo de escuela o institución educativa sostenible?

$1 \supseteq$ No

$2 \supseteq$ Sí, ha iniciado un período de reflexión en torno a ello

$3 \supseteq$ Sí, ya lo ha diseñado

14. ¿Se ha realizado en el centro alguna ecoauditoría?

$1 \supseteq \mathrm{Sí}^{\prime}$

$2 \supseteq$ No

$3 \supseteq$ Está previsto realizar alguna en breve

\section{B. La Educación para el desarrollo sostenible en el centro}

15. ¿Se han incluido en las programaciones de aula cuestiones y actividades en relación con la educación ambiental para el clesarrollo sostenible?

$1 \supseteq S i ́$, como tema transversal/materia optativa en el nivel de primaria/secundaria

$2 \supseteq$ Sí, como parte del contenido de alguna/s área/s curricular/es

$3 \supseteq$ No hay cuestiones ni activiclades previstas en las programaciones de aula 
LA ESCLELA Y FL DESARROLLO HL MA YO SOSTENIBLE: RETOS EDLCATIY( I \IVEL LOCAL.

16. ¿Organiza el centro actividades extra curriculares complementarias en relación a la educación para el clesarrollo sostenible (ej.: día del árbol, jornada de solidaridad, semana de la paz...)?

$1 \supseteq S i ́$ (inclicar cuáles y la frecuencia)

$2 \supseteq$ No

17. ¿Ha recibido el centro alguna ayuda o subvención de instituciones públicas o privadas para la realización de proyectos educativos medio-ambientales?

$1 \supseteq$ No

$2 \supseteq$ Sí, de instituciones públicas

$3 \supseteq$ Sí, de instituciones privadas

$4 \supseteq$ Ha solicitado subvención pero no se le ha concedido

18. En el centro ¿hay algún tipo de actuación conjunta en materia de educación ambiental y desarrollo sostenible?

$1 \supseteq$ No hay actuaciones conjuntas

$2 \supseteq$ Sí, entre profesores de diferentes materias, niveles y/grupos

$3 \supseteq$ Sí, entre profesores y AMPA

$4 \supseteq$ Sí, entre profesores y alumnos

$5 \supseteq$ Otros (especificar)

19. El centro educativo ¿ha realizado, está realizando o va a realizar alguna eco auditoría educativa integrada en el currículum?

$1 \supseteq$ No

$2 \supseteq$ Sí, como parte del contenido curricular de un tema transversal en Primaria

$3 \supseteq$ Sí, como una actividad complementaria

$4 \supseteq$ No, pero considero que se debería realizar

\section{Participación del centro en el desarrollo sostenible del municipio local}

20. ¿Conoce usted qué es una Agenda 21 local?

$1 \supseteq \mathrm{Sí}^{2}$

$2 \supseteq$ No demasiado (algo) o vagamente

$3 \supseteq$ No

21. El municipio al que pertenece el centro ¿ha iniciado un proceso para la elaboración de su Agenda 21 local?

$1 \supseteq$ No lo sé

$2 \supseteq$ No

$3 \supseteq$ Sí

$4 \supseteq$ Creo que tiene previsto iniciarlo en breve

22. La iniciativa de implantar y desarrollar una Agenda 21 local proviene de

$1 \supseteq$ El Ayuntamiento

$2 \supseteq$ Los agentes educativos locales (profesores, CEFIRE ...)

$3 \supseteq$ Otros (inclicar cuáles)

$+\supseteq$ Nolo sé 
23. ¿Funciona o se está creando en el municipio un foro de Participación Ciudadana para la implantación y desarrollo de su Agenda 21 local?

$$
\begin{aligned}
& 1 \supseteq \text { Sí } \\
& 2 \supseteq \text { No } \\
& 3 \supseteq \text { No lo sé }
\end{aligned}
$$

24. En caso afirmativo, ¿participa en el foro algún representante del centro?

$$
\begin{aligned}
& 1 \supseteq \mathrm{Sí} \\
& 2 \supseteq \mathrm{No}
\end{aligned}
$$

25. En caso de no participar, ¿estaría el centro dispuesto a delegar en un representante del mismo la participación en el foro de debate del Municipio para impulsar el desarrollo sostenible local?

$1 \supseteq \mathrm{No}$

$2 \supseteq$ Sí, muy dispuesto

$3 \supseteq$ Creo que sí, pero con dificultades (especificar cuáles)

26. ¿Se realizan desde el foro debates y se toman acuerdos en relación al proceso de implantación de la Agenda 21 local (identificación de problemas, prioridad de problemas a tratar, propuesta de acciones...)?

$$
\begin{aligned}
& 1 \supseteq \text { No } \\
& 2 \supseteq S_{1} \\
& 3 \supseteq \text { No lo sé }
\end{aligned}
$$

27. Señale el tipo de actores que participan en el foro del municipio:

$\begin{array}{ll}1 \supseteq \text { Cargos políticos del Ayuntamiento } & 9 \supseteq \text { Profesionales } \\ 2 \supseteq \text { Cargos técnicos del Ayuntamiento } & 10 \supseteq \text { Empresarios } \\ 3 \supseteq \text { Representantes de la industria } & 11 \supseteq \text { Sindicatos } \\ 4 \supseteq \text { Grupos ecologistas } & 12 \supseteq \text { ONGs } \\ 5 \supseteq \text { Asociaciones de vecinos } & 13 \supseteq \text { Representantes jubilados } \\ 6 \supseteq \text { Representantes centros educativos } & 14 \supseteq \text { Otros } \\ 7 \supseteq \text { Representantes juveniles } & 15 \supseteq \text { Lo desconozco } \\ 8 \supseteq \text { Profesionales } & \end{array}$


28. Los participantes en el foro del municipio itienen influencia en las decisiones ambientales finalmente adoptadas por el Ayuntamiento?

$1 \supseteq$ Creo que ninguna

$2 \supseteq$ Tienen una influencia relativa

$3 \supseteq$ Tienen mucha influencia

$4 \supseteq$ No lo sé

29. El representante educativo de su centro en el Foro de Participación Ciudadana de la localidad (municipio, pueblo o ciudad) ¿informa al centro educativo de los debates, propuestas de acción y acuerdos tomados en el curso de las reuniones?

$1 \supseteq$ El Centro no tiene un representante en el foro

$2 \supseteq$ Sí tiene representante, pero no puede asistir a todas las reuniones

$3 \supseteq$ Sí tiene representante y asiste a las reuniones, pero no hay establecidos cauces desde los que informar del contenido de las mismas

$4 \supseteq$ Sí tiene representante, asiste a las reuniones e informa del contenido de las mismas al Consejo Escolar

$5 \supseteq$ Otra (especificar)

30. Las propuestas de acción emitidas desde el Foro de Participación Ciudadana ¡tienen alguna aplicación, se están aplicando o se van a aplicar en su centro educativo?

$1 \supseteq$ No

$2 \supseteq$ Sí

$3 \supseteq$ No lo sé

31. Indique las acciones que usted cree que podrían hacerse en su centro educativo para contribuir al desarrollo sostenible de la localidad

32. Indique las dificultades que usted cree que se pueden tener en el centro para realizar las acciones arriba indicadas: 